Research Article

\title{
Semiconductor Quantum Dots $(\mathrm{CdX}, \mathrm{X}=\mathrm{S}$, Te, Se) Modify Titanium Dioxide Nanoparticles for Photodynamic Inactivation of Leukemia HL60 Cancer Cells
}

\author{
Qilin Pan, ${ }^{1}$ Miaomiao Li, ${ }^{1}$ Mucang Xiao, ${ }^{1}$ Yulu He, ${ }^{1}$ Guangyu Sun, ${ }^{1}$ Ting Xue, ${ }^{1}$ \\ Youhuan Luo, ${ }^{1}$ Li Chen, ${ }^{2}$ Baoquan $\mathrm{Ai},{ }^{1}{ }^{1}$ and Jianwen Xiong ${ }^{1}$ \\ ${ }^{1}$ School of Physics and Telecommunication Engineering, South China Normal University, Guangzhou 510006, China \\ ${ }^{2}$ School of Physics and Optoelectronic Engineering, Guangdong University of Technology, Guangzhou 510006, China \\ Correspondence should be addressed to Jianwen Xiong; jwxiong@scnu.edu.cn
}

Received 12 August 2021; Revised 24 October 2021; Accepted 3 November 2021; Published 15 December 2021

Academic Editor: Mazeyar Parvinzadeh Gashti

Copyright (c) 2021 Qilin Pan et al. This is an open access article distributed under the Creative Commons Attribution License, which permits unrestricted use, distribution, and reproduction in any medium, provided the original work is properly cited.

\begin{abstract}
Titanium dioxide nanoparticles $\left(\mathrm{TiO}_{2}-\mathrm{NPs}\right)$ are highly efficient photosensitizers in traditional photodynamic therapy (PDT). The particle size of $\mathrm{TiO}_{2}$-NPs is small, only about $20 \mathrm{~nm}$. However, the demands of ultraviolet light (UV) excitation feature shallow tissue penetration depth and may lead to severe tissue photon damage. Thus, in this research, $\mathrm{TiO}_{2}-\mathrm{NPs}_{\text {are }}$ modified with semiconductor quantum dots (QDs) $\mathrm{CdX}(\mathrm{X}=\mathrm{S}, \mathrm{Te}, \mathrm{Se})$ in various methods, such as ultrasonic, hydrothermal, sol-gel, aqueous phase, and hydrolysis precipitation. The transmission electron microscopy (TEM) images show that the size of $\mathrm{CdSe}^{-\mathrm{TiO}_{2}}$ is ranging from 6 to $14 \mathrm{~nm}$. The ultraviolet-visible (UV-Vis) spectrum demonstrates that the CdX $(\mathrm{X}=\mathrm{S}, \mathrm{Te}, \mathrm{Se})$ modification can successfully extend the absorption range of $\mathrm{TiO}_{2}$-NPs into a different visible light region. CdSe QDs have the narrowest band gap compared with $\mathrm{CdX}(\mathrm{X}=\mathrm{S}, \mathrm{Te}, \mathrm{Se})$ QDs. Visible light-activated $\mathrm{CdSe}-\mathrm{TiO}_{2}$ nanocomposite shows the highest PDT inactivation efficiency toward HL60 cells compared with $\mathrm{CdX}-\mathrm{TiO}_{2}$. The photogenerated carrier separation efficiency of CdSe$\mathrm{TiO}_{2}$ nanocomposite is the highest shown in a fluorescence spectrum (FS). Furthermore, when conjugated with folic acid (FA), the prepared FA-CdX-TiO $2(\mathrm{X}=\mathrm{S}$, Se) exhibits excellent cancer-targeting ability during PDT treatment. Optimum PDT efficiency of FA-CdSe- $\mathrm{TiO}_{2}$ indicates that photocatalytic and targeting ability is much higher than pure $\mathrm{TiO}_{2}$ and $\mathrm{CdSe}_{-} \mathrm{TiO}$. Our results provided a detailed investigation on the PDT performance of $\mathrm{CdX}(\mathrm{X}=\mathrm{S}, \mathrm{Te}, \mathrm{Se})$ modified $\mathrm{TiO}_{2}$ and may act as a guide for further design of highly targeted performance visible-light response $\mathrm{TiO}_{2}-\mathrm{NPs}$.
\end{abstract}

\section{Introduction}

Photodynamic therapy (PDT) is a nontoxic, noninvasive treatment [1]. Photodynamic therapy is based on the local or systemic administration of photosensitizer, which accumulates intensively in pathological tissues [2-4]. $\mathrm{TiO}_{2}$ is the most common photocatalyst and photosensitizer with the advantages of low cost, good chemical stability, low toxicity, etc. [5-8]. The holes and electrons generated by $\mathrm{TiO}_{2}$ have excellent oxidation and reduction abilities, respectively, under the ultraviolet light irradiation [9, 10]. However, due to the high band gap energy $(3.2 \mathrm{eV})$ of $\mathrm{TiO}_{2}$, the visible light response is ineffective and fast recombination of the electron-hole generated on the surface, which limits the PDT efficiency of titanium dioxide in practical application $[11,12]$.

As reported in our previous work, coupling $\mathrm{TiO}_{2}$ with low band gap energy metal or nonmetal to form a heterostructure is a feasible strategy to extend the visible light response range of $\mathrm{TiO}_{2}$-based nanocomposites and thus improve the photocatalytic performance [13-16]. CdS, CdSe, and CdTe belong to the II-VI group cadmium-based quantum dot material $[17,18]$. Previous reports have shown that the physical size of QDs with a high specific surface area is smaller than the Bohr radius of excitons. With low band gap energy, semiconductor quantum dots $\mathrm{CdX}(\mathrm{X}=\mathrm{S}, \mathrm{Te}$, $\mathrm{Se})$ are also more resistant to photobleaching than organic dyes and fluorescent proteins $[19,20]$. A lot of luminescent 
materials which were resistant to photobleaching such as lanthanide-doped upconversion nanoparticles were used in near-infrared (NIR) excitation as biolabelling in human cervical cancer (HeLa) cells $[21,22]$. However, the main problem of these materials was the low quantum efficiency at visible emission. Ruan et al. studied that CdS QDs had an illumination wavelength for photoelectrochemical generation of about $410 \mathrm{~nm}$ and were applied in a biosensor [23]. Guo et al. investigated that Daunorubicin-Loaded CdTe QDs enhanced the therapeutic effects of myelodysplastic syndromes to prevent acute leukemia from occurring [24]. Corredor et al. found that CdSe showed the best performance for hydrogen production compared with CdTe QDs [25]. Hua et al. developed strongly coupled CdX (X=S, Se and $\mathrm{Te}$ ) quantum dots $/ \mathrm{TiO}_{2}$ nanocomposites, which had good performance in photocatalytic degradation of benzene [26]. Nideep et al. investigated the good photovoltaic performance of $\mathrm{CdX}(\mathrm{X}=\mathrm{S}, \mathrm{Te}, \mathrm{Se}) \mathrm{QD}$ solar cells [17]. Bansal et al. compared the visible light absorption spectra of $\mathrm{CdX}$ $(\mathrm{X}=\mathrm{S}, \mathrm{Te}, \mathrm{Se})$ nanospheres; CdTe was the most efficient at absorbing solar energy [27]. Due to the lack of research on photodynamic therapy about $\mathrm{CdX}-\mathrm{TiO}_{2}(\mathrm{X}=\mathrm{S}, \mathrm{Te}, \mathrm{Se})$ NPs, therefore, it is necessary to research the $\mathrm{CdX}-\mathrm{TiO}_{2}$ $(\mathrm{X}=\mathrm{S}, \mathrm{Te}, \mathrm{Se}) \mathrm{NP}$-mediated PDT.

At present, the relapse rate of leukemia is high, and the disease cure rate should be improved [28]. Acute myeloid leukemia (AML) stem cells have abilities of highly selfrenewal [29]. HL60 cells are common human AML cells. Earlier studies reveal that folate receptor- $\beta$ (FR- $\beta$ ) was overexpressed in promyelocytic leukemia [30-32]. Most investigators find that FA can specifically combine with folate receptors (FR) that are overexpressed on the cancer cell cytomembrane but are rarely expressed in normal blood cells [33-35]. Even though $\mathrm{CdX}(\mathrm{X}=\mathrm{S}, \mathrm{Te}, \mathrm{Se})$ modified $\mathrm{TiO}_{2}$-NPs have potential in various drug delivery applications, a major challenge is its toxicity and nonspecific targeting. Most photosensitizers accumulate in normal and tumor tissue indiscriminately in nonspecific PDT, leading to the decrease in therapeutic effectiveness. So HL60 cells were used to evaluate the PDT efficiency of FA-CdX-TiO 2 nanocomposite. The surface of nanocomposites modified with FA can achieve targeting performance. In order to demonstrate $\mathrm{FA}-\mathrm{CdX}-\mathrm{TiO}_{2}$ nanocomposite with higher PDT efficiency, we should evaluate the size, morphology, spectral response range, lower dark toxicity, and other physicochemical properties by TEM, X-Ray Diffraction (XRD), UV-Vis, Fourier transform infrared spectroscopy (FT-IR), and so on.

Our studies further explore and reveal the mechanism of high photocatalytic activity, cancer-targeting functionality, and potential therapeutic effect of $\mathrm{CdX}-\mathrm{TiO}_{2}$ nanocomposite modified with folic acid on PDT inactivating HL60 cells in vitro (Figure 1$)$. $\mathrm{CdX}(\mathrm{X}=\mathrm{S}, \mathrm{Te}, \mathrm{Se})$ modification can improve the PDT inactivation efficiency of $\mathrm{TiO}_{2}-\mathrm{NPs}$ in visible light irradiation. When $\mathrm{CdX}-\mathrm{TiO}_{2}$ nanocomposite is conjugated with FA, it can exhibit excellent cancer-targeting ability in PDT inactivation. Our results provided mass of data investigation on PDT performance of $\mathrm{CdX}(\mathrm{X}=\mathrm{S}$, Te, Se) modified $\mathrm{TiO}_{2}$ and may act as a guide for further design of high targeting ability $\mathrm{TiO}_{2}-\mathrm{NPs}$ in visible light response.

\section{Materials and Methods}

2.1. Chemicals and Apparatus. HL60 cells were kindly provided by the Department of Medicine of Sun Yat-sen University. RPMI medium 1640 and fetal calf serum (FCS) were obtained from Gibco BRL (USA). Fluo-3 AM and phosphate-buffered saline (PBS) were obtained from Sigma (USA). Cell Counting Kit-8 (CCK-8) assays were purchased from Dojindo (Japan). $\mathrm{TiO}_{2}-\mathrm{NPs}$ were purchased from Degussa (GER). Trypan blue was obtained from Invitrogen (USA).

The apparatuses used in this research are as follows: ZEISS Ultra-55 scanning electron microscope (Carl Zeiss, Germany), JEM-2100HR transmission electron microscope (JEOL, Japan), U-3010 UV-visible spectrophotometer (Hitachi, Japan), F-4500 Fluorescence Spectrophotometer (Hitachi, Japan), the Countess automated cell counter (Invitrogen, USA), Model 680 Microplate Reader (Bio-Rad, USA), HH.CP-TW80 CO 2 incubator (Bluepard, China), lab-assembled PDT light reaction chamber, lab-assembled $410 \mathrm{~nm}$ LED light source, BRUKER D8 ADVANCE X-ray powder diffractometer (XRD) (Bruker, Germany), BS124S Electronic Scales (Sartorius, GER), SK2510LHC Ultrasonic Cleaner (KUDOS, China), SW-CJ Standard Clean Bench (Suzhou Antai Airtech Co., Ltd., China), LPE-1A Laser Power Meter (Physcience Opto-Electronics, Beijing), Eppendorf (Finland), 96-well culture plates (Costar, USA), and so on.

2.2. Light Source. The emission spectrum of light-emitting diode (LED) light source in the photodynamic irradiation chamber used in this experiment shows that emitting light from 400 to $420 \mathrm{~nm}$ in the visible-light region and the emission peak is located at $409.97 \mathrm{~nm}$ (Figure 2). The luminous power at the position of the sample was $18 \mathrm{~J} / \mathrm{cm}^{2}$ as measured with a photodiode.

2.3. Preparation of CdS-Based Nanocomposite A. Isopropyl titanate $\left(\mathrm{C}_{12} \mathrm{H}_{28} \mathrm{O}_{4} \mathrm{Ti}\right.$, CAS No. 546-68-9, purity 95\%) was purchased from Shanghai Macklin Biochemical Technology Co., Ltd., China. Cadmium chloride hydrate $\left(\mathrm{CdCl}_{2} \cdot \mathrm{xH}_{2} \mathrm{O}\right.$, CAS No. 654054-66-7, purity 95\%) was purchased from Aladdin Industrial Co., China. Ethylenediamine $\left(\mathrm{C}_{2} \mathrm{H}_{8} \mathrm{~N}_{2}\right.$, CAS No. 6780-13-8, purity 98\%), carbon disulfide $\left(\mathrm{CS}_{2}\right.$, CAS No. 30860-31-2, purity 99\%), and anhydrous ethanol $\left(\mathrm{C}_{2} \mathrm{H}_{6} \mathrm{O}\right.$, CAS No. 64-17-5) were purchased from Tianjin Zhiyuan Chemical Industry Ltd., China. All reagents were of analytical purity and used without further purification.

The water temperature in the ultrasonic cleaner was set to $35^{\circ} \mathrm{C}$. Then, $40 \mathrm{~mL}$ of deionized water at $14.8^{\circ} \mathrm{C}$ was added to the beaker and the beaker was placed in the cleaner. Dropping $0.6 \mathrm{~mL}$ of ethylenediamine and $0.2 \mathrm{~mL}$ of carbon disulfide into the beaker. Ultrasonic dispersion was carried out for 2 minutes $(40 \mathrm{kHz}$, power $100 \mathrm{~W})$; then, $10 \mathrm{~mL}$ of $0.015 \mathrm{~g} / \mathrm{mL} \mathrm{CdCl}_{2} \cdot \mathrm{xH}_{2} \mathrm{O}$ aqueous solution was dropped, and ultrasound continued for 10 minutes. The ultrasonic cleaner increased the water temperature from $35^{\circ} \mathrm{C}$ to $71^{\circ} \mathrm{C}$, and the ultrasound continued for 30 minutes $(40 \mathrm{kHz}$, power $100 \mathrm{~W})$. Isopropyl titanate $(0,0.2,0.4,0.6$, and $1.0 \mathrm{~mL})$ was 


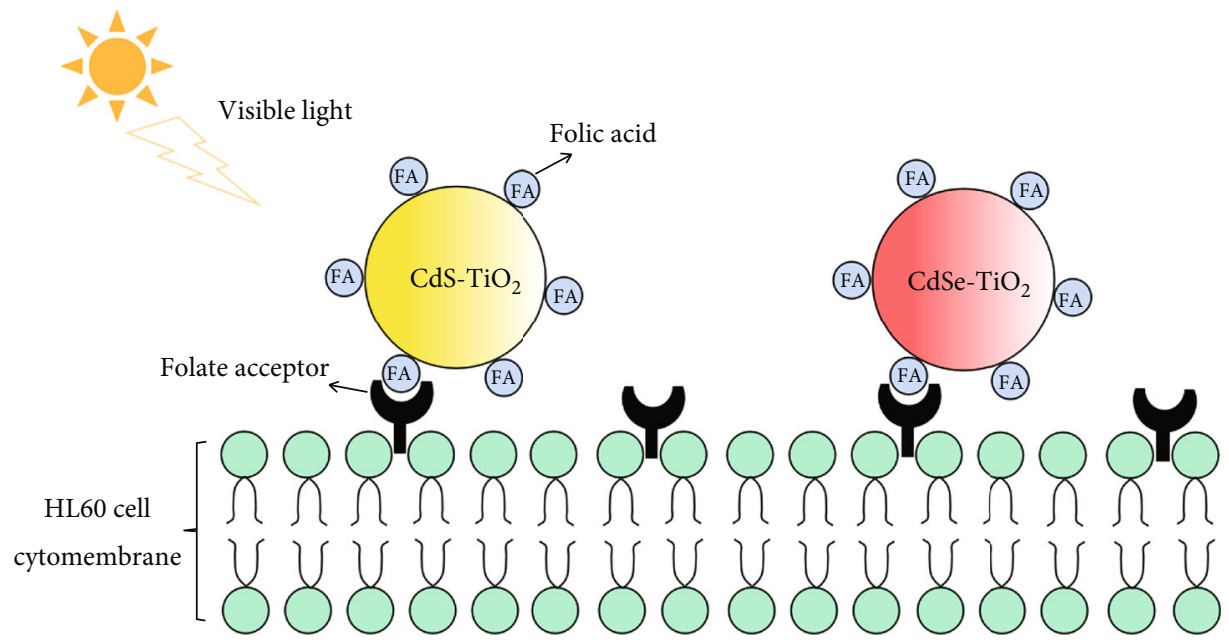

Figure 1: The possible mechanism of $\mathrm{CdX}(\mathrm{X}=\mathrm{S}, \mathrm{Te}, \mathrm{Se})$-based nanocomposites modified with folic acid with enhanced targeting functionality.

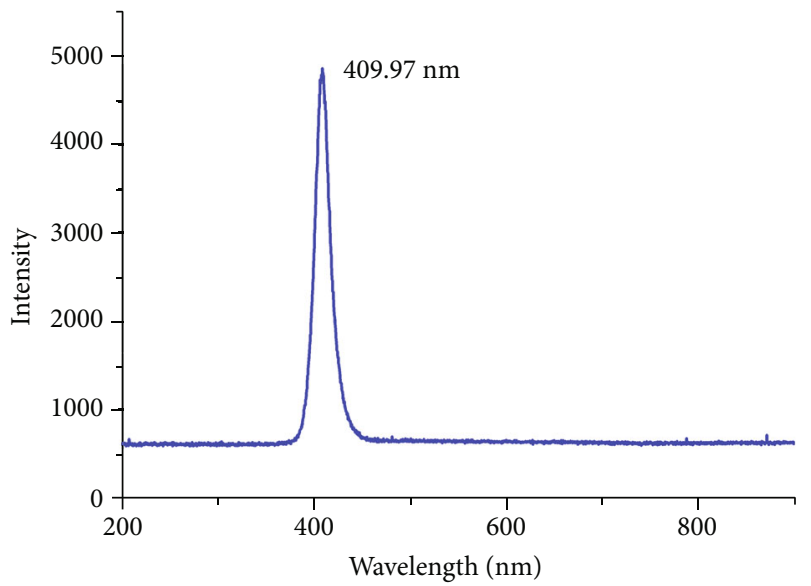

FIgURE 2: The emission spectra of blue LED array source.

added drop by drop, the temperature was controlled unchanged, and the ultrasound continued for 1.5 hours $(40 \mathrm{kHz}$, power $100 \mathrm{~W})$. The precipitate was centrifugally separated $(10000 \mathrm{r} / \mathrm{min}, 10$ minutes), washed once with deionized water, twice with anhydrous ethanol, and airdried at room temperature. The obtained precipitate was calcined in the muffle furnace at $500^{\circ} \mathrm{C}$ for 4 hours, and grinding for 30 minutes, filtered through a $0.22 \mu \mathrm{m}$ membrane filter, and sterilized to prepare the sample. The obtained samples were labeled as sample $\mathrm{TiO}_{2}, 0.2,0.4,0.6$, and 1.0, depending on the amount of $\mathrm{TiO}_{2}$ precursor isopropyl titanate added.

\subsection{Different Preparation Methods of CdTe-Based Titanium Dioxide Nanocomposites. CdTe-based nanocomposite A: the water-soluble CdTe quantum dots were prepared by the hydrothermal method. The $\mathrm{TiO}_{2}$-CdTe nanocomposite was prepared by ultrasonic mixing. CdTe-based nanocom- posite $\mathrm{B}$ : the core-shell structure of $\mathrm{CdTe} / \mathrm{TiO}_{2}$ was prepared by the sol-gel method. CdTe was coated inside the $\mathrm{TiO}_{2}$. CdTe-based nanocomposite C: CdTe was coated with car- boxylic acid to form $\mathrm{CdTe} / \mathrm{HS}-\mathrm{CH}_{2}-\mathrm{COOH}$ nanoparticle.}

2.4.1. Preparation of CdTe-Based Nanocomposite A. Tellurium (Te, CAS No. 13494-80-9, purity $>99.99 \%$ ) and sodium hydroxide ( $\mathrm{NaOH}$, CAS No. 1310-73-2, A.R.) were purchased from Tianjin Zhiyuan Chemical Industry Ltd., China. Sodium borohydride $\left(\mathrm{NaBH}_{4}\right.$, CAS No. 16940-66-2, purity $98 \%)$ and cadmium chloride $\left(\mathrm{CdCl}_{2}, \mathrm{CAS}\right.$ No. 10108-64-2, A.R.) were purchased from Aladdin Industrial Co., China. Thioglycolic acid $\left(\mathrm{C}_{2} \mathrm{H}_{4} \mathrm{O}_{2} \mathrm{~S}\right.$, CAS No. 68-11-1, A.R.) was purchased from Sigma-Aldrich, USA. All reagents were of analytical purity and used without further purification.

Referring to the method of Zhang et al. and making appropriate adjustments [36], poured tellurium powder and $\mathrm{NaBH}_{4}$ into the reaction flask, respectively, injected proper amount of water, reacting for half an hour under magnetic stirring. The reaction system is protected by nitrogen deoxygenation during the reaction process to obtain NaHTe solution. Thioglycolic acid was added into the aqueous solution of $\mathrm{CdCl}_{2}$ saturated with nitrogen, and the $\mathrm{pH}$ value of the solution was adjusted to about 9.5 by $\mathrm{NaOH}$. After stirring the solution with strong magnetic force for half an hour, NaHTe solution was added and magnetically stirred for reflux at $95^{\circ} \mathrm{C}$ for two hours. The experimental process was protected by nitrogen gas to obtain CdTe watersoluble QDs. After that, CdTe powder was obtained by centrifugation, drying, and grinding.

2.4.2. Preparation of CdTe-Based Nanocomposite B. Tellurium (Te, CAS No. 13494-80-9, purity $>99.99 \%$ ), sodium hydroxide (NaOH, CAS No. 1310-73-2, A.R.), ethylene glycol $\left(\mathrm{C}_{2} \mathrm{H}_{6} \mathrm{O}_{2}\right.$, CAS No. 107-21-1, A.R.), and anhydrous ethanol $\left(\mathrm{C}_{2} \mathrm{H}_{6} \mathrm{O}\right.$, CAS No. 64-17-5, A.R.) were purchased from Tianjin Zhiyuan Chemical Industry Ltd., China. Sodium borohydride $\left(\mathrm{NaBH}_{4}, \mathrm{CAS}\right.$ No. 16940-66-2, purity 98\%), cadmium chloride ( $\mathrm{CdCl}_{2}$, CAS No. 10108-64-2, A.R.), and acetylacetone $\left(\mathrm{C}_{5} \mathrm{H}_{8} \mathrm{O}_{2}\right.$, CAS No. 123-54-6, A.R.) were purchased from Aladdin Industrial Co., China. Isopropyl titanate $\left(\mathrm{C}_{12} \mathrm{H}_{28} \mathrm{O}_{4} \mathrm{Ti}\right.$, CAS No. 546-68-9, purity $\left.95 \%\right)$ was purchased from Shanghai Macklin Biochemical Technology 
Co., Ltd., China. Thioglycolic acid $\left(\mathrm{C}_{2} \mathrm{H}_{4} \mathrm{O}_{2} \mathrm{~S}\right.$, CAS No. 6811-1, A.R.) was purchased from Sigma-Aldrich, USA. All reagents were of analytical purity and used without further purification.

$\mathrm{NaHTe}$ solution was prepared by reduction of tellurium powder with sodium borohydride $\left(\mathrm{NaBH}_{4}\right)$ under nitrogen. Thioglycolic acid was added into the nitrogen-saturated $\mathrm{CdCl}_{2}$ solution, and the $\mathrm{pH}$ value of the solution was adjusted to about 11 with $4 \mathrm{~mol} / \mathrm{L} \mathrm{NaOH}$ solution. Then, the NaHTe solution was quickly added, and the solution was stirred evenly and refluxed in a water bath at $100^{\circ} \mathrm{C}$ for 1 hour to obtain water-soluble CdTe QDs. The whole process was in a nitrogen deoxygenation state.

$\mathrm{CdTe} / \mathrm{TiO}_{2}$ nanocomposite was prepared by the sol-gel method. To synthesize titanium-containing solution with good dispersibility, the isopropyl titanate was added into ethylene glycol under magnetic stirring for 5 hours. After $2 \mathrm{~mL}$ of CdTe solution was added dropwise to $280 \mathrm{~mL}$ of acetylacetone under magnetic stirring and stirred evenly, then, $15 \mathrm{~mL}$ of titanium-containing solution was added dropwise slowly, and magnetic stirring was continued for 15 minutes and left to set for at least 30 minutes. Then, the samples were centrifuged in a $10000 \mathrm{r} / \mathrm{min}$ high-speed centrifuge for 10 minutes. After the precipitate was dissolved in anhydrous ethanol for ultrasonic dispersion, it was centrifuged again and repeated for three times to obtain $\mathrm{CdTe} /$ $\mathrm{TiO}_{2}$ nanocomposite.

2.5. Different Preparation Methods of CdSe-Based Nanocomposites. CdSe-based nanocomposite A: CdSe was coated with carboxylic acid to form $\mathrm{CdSe} / \mathrm{HS}-\mathrm{CH}_{2}-\mathrm{COOH}$ nanoparticle. CdSe-based nanocomposite $\mathrm{B}$ : the CdSedoped anatase $\mathrm{TiO}_{2}\left(\mathrm{CdSe} / \mathrm{TiO}_{2}\right)$ was synthesized by the ultrasonic-driven method.

2.5.1. Preparation of CdSe-Based Nanocomposite B. The hydrazine monohydrate $\left(\mathrm{H}_{4} \mathrm{~N}_{2} \cdot \mathrm{H}_{2} \mathrm{O}\right.$, CAS No. 7803-57-8, purity $85 \%$ ) and the ammonium hydroxide solution $\left(\mathrm{NH}_{3} \cdot \mathrm{H}_{2} \mathrm{O}\right.$, CAS No. 1336-21-6, purity $\left.25 \%\right)$ were purchased from Tianjin Zhiyuan Chemical Industry Ltd., China. The sodium sulfite anhydrous $\left(\mathrm{Na}_{2} \mathrm{SO}_{3}\right.$, CAS No. 7757-83-7, A.R.), cadmium nitrate $\left(\mathrm{Cd}\left(\mathrm{NO}_{3}\right)_{2} \cdot 4 \mathrm{H}_{2} \mathrm{O}\right.$, CAS No. 1002268-1, A.R.), acetic acid $\left(\mathrm{CH}_{3} \mathrm{COOH}\right.$, CAS No. 64-19-7, A.R.), and selenium (Se, CAS No. 7782-49-2, purity 99.99\%) were purchased from Shanghai Macklin Biochemical Technology Co., Ltd., China. All reagents were of analytical purity and used without further purification.

In a $250 \mathrm{~mL}$ conical flask, anhydrous sodium sulfite $\left(\mathrm{Na}_{2} \mathrm{SO}_{3}\right)(0.315 \mathrm{~g})$ was dissolved in $50 \mathrm{~mL}$ distilled water, and selenium (Se) (0.1974 g) was added to the mixed solution to obtain selenosulfate solution $\left(\mathrm{Na}_{2} \mathrm{SeSO}_{3}\right)$ (about $0.0025 \mathrm{~mol})$. Then, $5 \mathrm{~mL}$ hydrazine hydrate $\left(\mathrm{H}_{4} \mathrm{~N}_{2} \cdot \mathrm{H}_{2} \mathrm{O}\right)$ solution was added to a $250 \mathrm{~mL}$ conical flask of the prepared selenosulfate solution $\left(\mathrm{Na}_{2} \mathrm{SeSO}_{3}\right)$ until the $\mathrm{pH}$ value of the solution reached 9.0 approximately. After cadmium nitrate $\mathrm{Cd}\left(\mathrm{NO}_{3}\right)_{2} \cdot 4 \mathrm{H}_{2} \mathrm{O}(1.5424 \mathrm{~g})$ and $\mathrm{NH}_{3} \cdot \mathrm{H}_{2} \mathrm{O}(3 \mathrm{~mL})$ were mixed, the mixed solution was added to the prepared $\mathrm{Na}_{2} \mathrm{SeSO}_{3}$, and then, water-bath ultrasound was performed for 2 hours in an ultrasonic cleaning tank (operating fre- quency: $59 \mathrm{kHz}$ ). It could be observed that the turbid solution gradually changed from black to bright yellow and then to bright orange which was the CdSe nanoparticle solution. Then, $0.9568 \mathrm{~g}, 0.4784 \mathrm{~g}$, and $0.2392 \mathrm{~g}$ of $\mathrm{TiO}_{2}$ were added into the prepared CdSe nanoparticle solution according to the doping mass ratios of $\mathrm{CdSe}$ doped $\mathrm{TiO}_{2}$ of one to two, one to one, and two to one, respectively, and the mixed solution of CdSe nanoparticles with $\mathrm{TiO}_{2}$ was subjected to ultrasonic radiation. Finally, the samples with different doping ratios of $\mathrm{CdSe}$ to $\mathrm{TiO}_{2}$ equaled 0.5 , CdSe to $\mathrm{TiO}_{2}$ equaled one, and $\mathrm{CdSe}$ to $\mathrm{TiO}_{2}$ equaled two were labeled as $\mathrm{CdSe} /$ $\mathrm{TiO}_{2}-0.5, \mathrm{CdSe} / \mathrm{TiO}_{2}-1$, and $\mathrm{CdSe} / \mathrm{TiO}_{2}-2$, respectively, through centrifugation and vacuum drying.

\subsection{Preparation of $C d X(X=S$, Se)-Based Nanocomposite Modified with Folic Acid}

2.6.1. Preparation of CdS-Based Nanocomposite B. Folic acid $\left(\mathrm{C}_{19} \mathrm{H}_{19} \mathrm{~N}_{7} \mathrm{O}_{6}\right.$, CAS No. 59-30-3, purity $\left.\geq 97 \%\right)$ was purchased from Sigma-Aldrich, USA. Sodium bicarbonate $\left(\mathrm{NaHCO}_{3}\right.$, CAS No. 144-55-8, A.R.) was purchased from Aladdin Industrial Co., China. Hydrochloric acid ( $\mathrm{HCl}, \mathrm{CAS}$ No. 7647-01-0, purity 37\%) and sodium hydroxide $(\mathrm{NaOH}$, CAS No. 1310-73-2, A.R.) were purchased from Tianjin Zhiyuan Chemical Industry Ltd., China. All reagents were of analytical purity and used without further purification.

Firstly, $420 \mathrm{mg}$ of the sodium bicarbonate solution was weighed, then added into $50 \mathrm{~mL}$ of deionized water, and adjusted the $\mathrm{pH}$ of the solution to 5.5 with sodium hydroxide and hydrochloric acid. Then, a proper amount of folic acid was added into the prepared sodium bicarbonate solution, and the mixture was uniformly mixed with a magnetic stirrer, labbed as solution A. The same amount of the prepared $\mathrm{CdS}-\mathrm{TiO}_{2}$ nanocomposite (CdS-based nanocomposite A) was added into $4.5 \mathrm{~mL}$ of deionized water and dispersed by ultrasound for 15 minutes, labbed as solution $B$. The solution $\mathrm{B}$ was added dropwise to solution A while stirring in the ultrasound, and the mixed solution was treated in dark and continuously stirred at room temperature for 24 hours. The obtained turbidity mixture was centrifuged, washed twice with saturated sodium bicarbonate solution and deionized water, and then air-dried at room temperature. Finally, the sample was filtered through a $0.22 \mu \mathrm{m}$ membrane filter and sterilized to obtain $\mathrm{FA}-\mathrm{CdS}-\mathrm{TiO}_{2}$ nanocomposite (CdS-based nanocomposite B).

2.6.2. Preparation of CdSe-Based Nanocomposite C. Folic acid $\left(\mathrm{C}_{19} \mathrm{H}_{19} \mathrm{~N}_{7} \mathrm{O}_{6}\right.$, CAS No. 59-30-3, purity $\left.\geq 97 \%\right)$ and thioglycolic acid $\left(\mathrm{C}_{2} \mathrm{H}_{4} \mathrm{O}_{2} \mathrm{~S}\right.$, CAS No. 68-11-1, A.R.) were purchased from Sigma-Aldrich, USA. Selenium (Se, CAS No. 7782-49-2, purity $>99.99 \%$ ) and sodium sulfite anhydrous $\left(\mathrm{Na}_{2} \mathrm{SO}_{3}\right.$, CAS No. 7757-83-7, A.R.) were purchased from Shanghai Macklin Biochemical Technology Co., Ltd., China. Tetrabutyl titanate $\left(\mathrm{C}_{16} \mathrm{H}_{36} \mathrm{O}_{4} \mathrm{Ti}\right.$, CAS No. 5593-704 , purity $\geq 99 \%)$, anhydrous ethanol $\left(\mathrm{C}_{2} \mathrm{H}_{6} \mathrm{O}\right.$, CAS No. 6417-5, A.R.), hydrochloric acid ( $\mathrm{HCl}, \mathrm{CAS}$ No. 7647-01-0, $37 \%$ ), and sodium hydroxide ( $\mathrm{NaOH}$, CAS No. 1310-73-2, A.R.) were purchased from Tianjin Zhiyuan Chemical Industry Ltd., China. Cadmium chloride $\left(\mathrm{CdCl}_{2}, \mathrm{CAS}\right.$ No. 
10108-64-2, A.R.) and sodium bicarbonate $\left(\mathrm{NaHCO}_{3}, \mathrm{CAS}\right.$ No. 144-55-8, A.R.) were purchased from Aladdin Industrial Co., China. All reagents were of analytical purity and used without further purification.

$\mathrm{CdSe}-\mathrm{TiO}_{2}$ nanocomposite was prepared by hydrolytic precipitation method. After $0.13196 \mathrm{~g}$ CdSe powder was weighed and added with $30 \mathrm{~mL}$ of anhydrous ethanol, the dispersion system A was obtained by ultrasonic vibration for 1 hour. Then, $1.761 \mathrm{~mL}$ tetrabutyl titanate was dropwise added to solution A with stirring for 15 minutes to get dispersion system B. Next, $10 \mathrm{~mL}$ of water and anhydrous ethanol mixture in a volume ratio of one to five was added dropwise to solution B with continuously stirring for 1 hour. The precipitate was separated by centrifugation and further washed twice with distilled water and anhydrous ethanol, respectively, and air-dried at room temperature. The CdSe$\mathrm{TiO}_{2}$ nanocomposite was prepared by calcination in the muffle furnace at $500^{\circ} \mathrm{C}$ for 4 hours, grinding for 30 minutes, filtration, and sterilization.

Firstly, $840 \mathrm{mg}$ of sodium bicarbonate was dissolved in $100 \mathrm{~mL}$ of deionized water, $40 \mathrm{~mL}$ of the sodium bicarbonate solution was measured and adjusted the $\mathrm{pH}$ value to 5.5 using sodium hydroxide and hydrochloric acid. A proper amount of folic acid was added into the prepared carbonic acid solution and stirred on a magnetic stirrer. A proper amount of $\mathrm{CdSe}-\mathrm{TiO}_{2}$ nanocomposite was added into $5 \mathrm{~mL}$ deionized water for ultrasonic dispersion. The prepared $\mathrm{CdSe}-\mathrm{TiO}_{2}$ nanocomposite suspension was added step by step to the folic acid solution under the ultrasonic environment. And the mixed solution was treated in the dark and continuously stirred at room temperature for 24 hours. Finally, the prepared FA-CdSe- $\mathrm{TiO}_{2}$ nanocomposite (CdSe-based nanocomposite $\mathrm{C}$ ) was washed twice with saturated sodium bicarbonate solution and deionized water, respectively.

2.7. Selection of Nanoparticle Concentration. The concentration range selected in our experiment is from 0.2 to $320 \mu \mathrm{g} /$ mL. Previous studies have shown that $\mathrm{TiO}_{2} \mathrm{NPs}$ did not affect HL60 cell viability at the concentration from 0 to $150 \mu \mathrm{g} / \mathrm{mL}[37,38]$. Higher than $150 \mu \mathrm{g} / \mathrm{mL}$ belongs to high concentration [39]. Working with high concentrations of nanoparticles possibly affects the normal cell viability and reduces the toxicological value of the results [40].

2.8. Cell Culture. Human leukemia HL60 cells were cultured in RPMI 1640 medium supplemented with 10\% fetal bovine serum (FBS) in a humidified incubator with $5 \% \mathrm{CO}_{2}$ at $37^{\circ} \mathrm{C}$. All experiments were performed using cells during the logarithmic growth phase. The cell concentration was measured using a Countess automated cell counter, and the cell density was adjusted to the required final concentration. Cell viability before treatment was always over $95 \%$.

2.9. Cell Viability Assay. The cell activity detection is by using the Model 680 Microplate Reader, the method of CCK-8 (Cell Counting Kit-8) with simple operation, high sensitivity, and good repeatability compared with traditional methods. To make the results more precise, a method of dual-wavelength testing is conducted, with $450 \mathrm{~nm}$ as the measuring wavelength and $630 \mathrm{~nm}$ as the reference wavelength to detect the cell activity of general steps: (1) the preparation of cell suspension, (2) cell suspension will join the 96-well culture plates and culture at a $37^{\circ} \mathrm{C}$ incubator for a period of time, (3) to join the appropriate amount of CCK8 agent, at $37^{\circ} \mathrm{C}$ incubator shading cultivation in four hours, and (4) determination of absorbance (OD value).

2.10. Statistical Analysis. Data were presented as means \pm SD (standard deviation) from three independent groups. Each experiment was repeated three times. SPSS22.0 statistical software was used to conduct the analysis of variance and the $t$-test for the comparison of multiple local mean. The value of $P$ smaller than 0.05 was considered statistically significant.

\section{Results and Discussion}

\subsection{Characterization of $C d X(X=S, T e, S e)$ - Based Nanocomposites}

3.1.1. TEM and Particle Size Studies. The morphology and particle sizes were observed by a JEM-2100HR transmission electron microscope, dipping a small amount of nanocomposites into deionized water and conducting ultrasonic treatment for 2 minutes. To take a drop of copper wire with a rubber head dropper, experiment will be carried out after drying. TEM is used to observe particle size and dispersion [41, 42]. Figures 3(a) and 3(b) show CdS QDs and coreshell structure of $\mathrm{CdS}-\mathrm{TiO}_{2}$ (CdS-based nanocomposite A) with relatively uniform dispersibility in water solution. The particle size of CdS QDs is from 13 to $21 \mathrm{~nm}$ shown in Figure $4(\mathrm{a})$, and $\mathrm{CdS}-\mathrm{TiO}_{2}$ nanocomposite is from 16 to $23 \mathrm{~nm}$ shown in Figure 4(b).

Figure 3(c) indicates the TEM image of CdTe watersoluble quantum dots with good dispersibility and stability in aqueous solution. CdTe QDs feature a size of from 3 to $5 \mathrm{~nm}$ shown in Figure 4(c). Figure 3(d) is the TEM image of $\mathrm{CdTe} / \mathrm{TiO}_{2}(\mathrm{CdTe}$-based nanocomposite $\mathrm{B})$ with a certain degree of dispersion. There are black particles inside the nanocomposites, and we suppose that CdTe is coated inside the $\mathrm{TiO}_{2}$. The size of CdTe-based nanocomposite $\mathrm{B}$ is about $80 \mathrm{~nm}$ as shown in Figure 4(d).

TEM images of CdSe QDs and $\mathrm{CdSe} / \mathrm{TiO}_{2}$ nanocomposite (CdSe-based nanocomposite B) are shown in Figures 3(e) and $3(f)$. It could be observed that the two kinds of nanoparticles are uniformly distributed with good monodispersity and spherical or quasi-spherical particle morphology. The size of CdSe nanoparticles mainly concentrated around $18 \mathrm{~nm}$ is shown in Figure 4(e), while the size of doped $\mathrm{CdSe} / \mathrm{TiO}_{2}$ nanocomposite mainly concentrated around $10 \mathrm{~nm}$ is shown in Figure 4(f). The ultrasonic driving method could effectively reduce the size of nanoparticles and promote the crystal transformation of nanoparticles, so as to obtain $\mathrm{CdSe} / \mathrm{TiO}_{2}$ nanocomposite with smaller particle size and improve the effective absorption of the material by cells. 


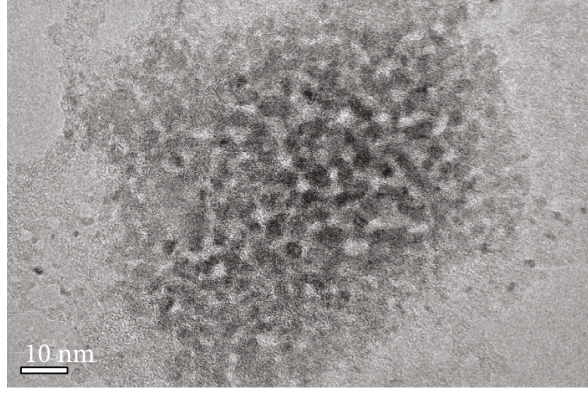

(a)

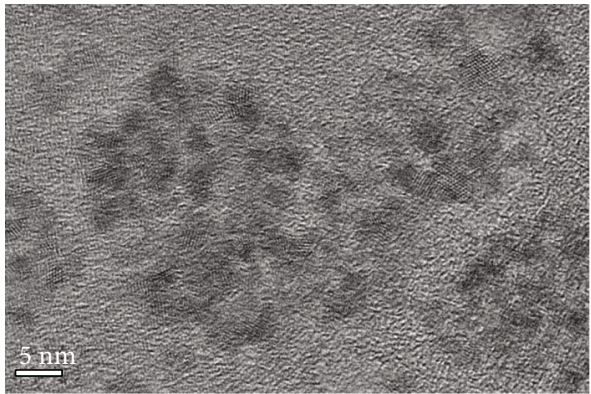

(c)

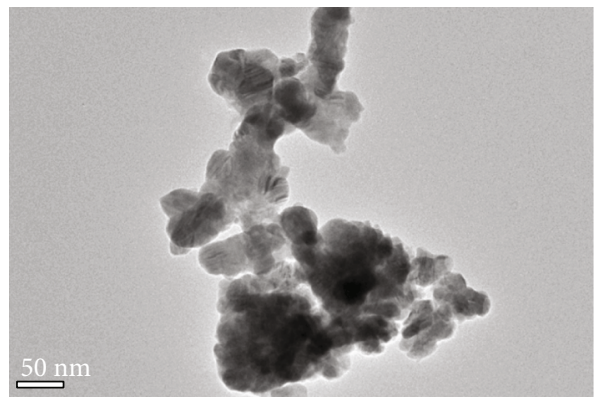

(e)

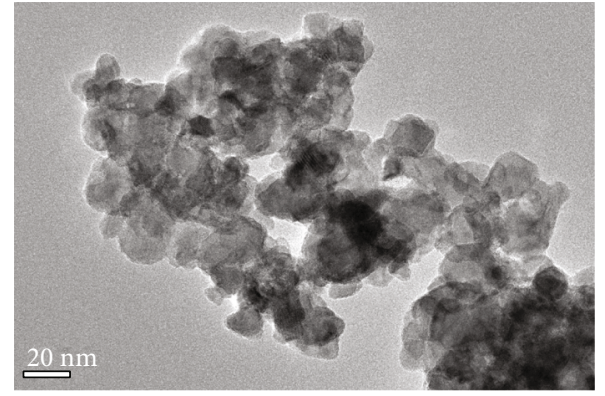

(b)

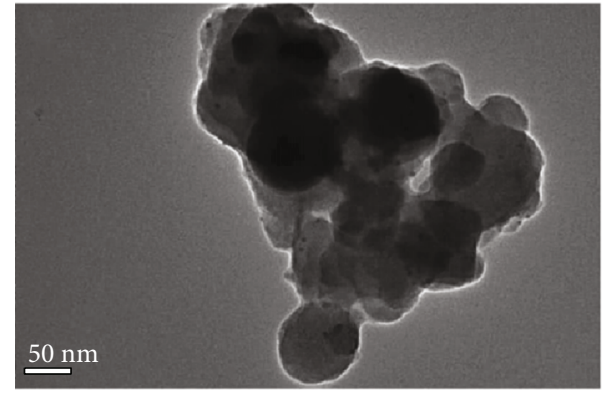

(d)

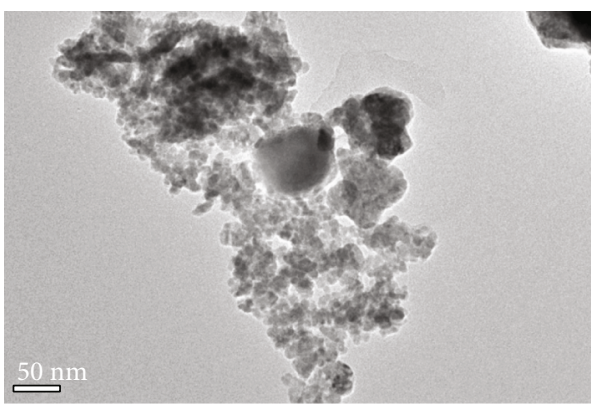

(f)

Figure 3: (a) The TEM image of CdS QDs; (b) the TEM image of CdS-TiO ${ }_{2}$ nanocomposite sample (CdS-based nanocomposite A); (c) the TEM image of CdTe QDs; (d) the TEM image of $\mathrm{CdTe}_{\mathrm{TiO}}$ nanocomposite (CdTe-based nanocomposite B); (e) the TEM image of CdSe QDs; (f) the TEM image of $\mathrm{CdSe} / \mathrm{TiO}_{2}$ nanocomposite (CdSe-based nanocomposite $\mathrm{B}$ ).

Studies have shown that nanocomposites with particle size less than $100 \mathrm{~nm}$ can meet the condition of entering cells, so the above nanocomposites prepared in our laboratory meet the size requirements of a photosensitizer.

3.1.2. X-Ray Diffraction. The crystallite size is calculated by the Scherrer formula [43]:

$$
D=\frac{K \lambda}{\beta \cos \theta},
$$

where $D$ is the crystalline size, $\lambda$ is the $\mathrm{X}$-ray wavelength $(0.1541 \mathrm{~nm}), K$ is the constant usually taken as $0.89, \theta$ is Bragg's angle $2 \theta=25.3^{\circ}$ for anatase phase titanium dioxide, and $\beta$ is the pure full width of the diffraction line at half of the maximum intensity.

XRD patterns of CdS- $\mathrm{TiO}_{2}$ nanocomposites (CdS-based nanocomposite A) are shown in Figure 5(a). According to the above formula (1), it was calculated that the average crystallite sizes were $15.1 \mathrm{~nm}$ for $\mathrm{CdS}-\mathrm{TiO}_{2}$ sample 0.2 nano- composites and $21.9 \mathrm{~nm}$ for CdS- $\mathrm{TiO}_{2}$ sample 1.0 nanocomposites. The data obtained by TEM analysis of CdS- $\mathrm{TiO}_{2}$ nanocomposites (Figure 3(b)) were consistent with XRD results. The average crystallite sizes were 17.0, 17.2, and $19.1 \mathrm{~nm}$ for $\mathrm{CdS}-\mathrm{TiO}_{2}$ sample pure $\mathrm{TiO}_{2}, 0.4$, and 0.6, respectively. The XRD diffraction peaks of the synthesized $\mathrm{CdS}-\mathrm{TiO}_{2}$ nanocomposite (CdS-based nanocomposite A) around $2 \theta$ of $25.1^{\circ}, 37.8^{\circ}, 48^{\circ}, 53.8^{\circ}$, and $55.1^{\circ}$ could be indexed to the characteristic peaks (101), (004), (200), (105), and (211) of anatase $\mathrm{TiO}_{2}$. Thus, the CdS- $-\mathrm{TiO}_{2}$ nanoparticles had the anatase phase. The crystal diffraction peak of CdS was mainly located between $25^{\circ}$ and $35^{\circ}$. The $2 \theta$ peaks of $27.2^{\circ}, 28.2^{\circ}, 36.8^{\circ}, 43.6^{\circ}$, and $51.8^{\circ}$ indicated that the CdS in the sample was mainly hexagonal.

XRD pattern of CdTe QDs (CdTe-based nanocomposite A) is shown in Figure 5(b); it had two diffraction peaks which are obvious but not spike and conformed to the characteristics of the small size of quantum dots. The XRD diffraction peaks around $2 \theta$ of $24.38^{\circ}, 40.31^{\circ}$, and $47.02^{\circ}$, which could be indexed to the characteristic peaks (111), 


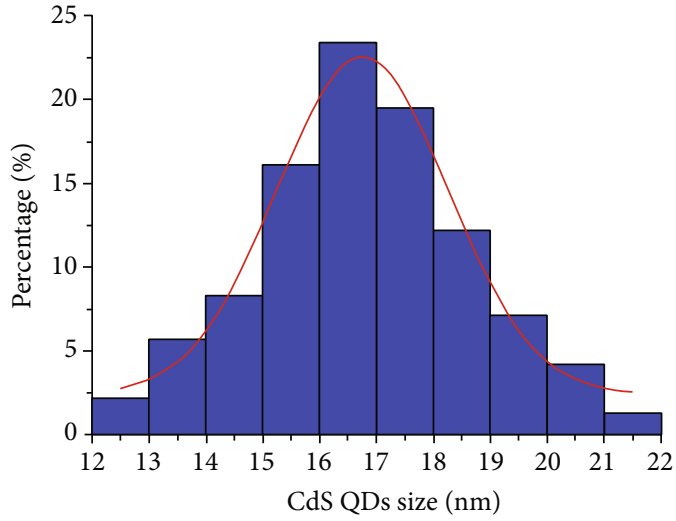

(a)

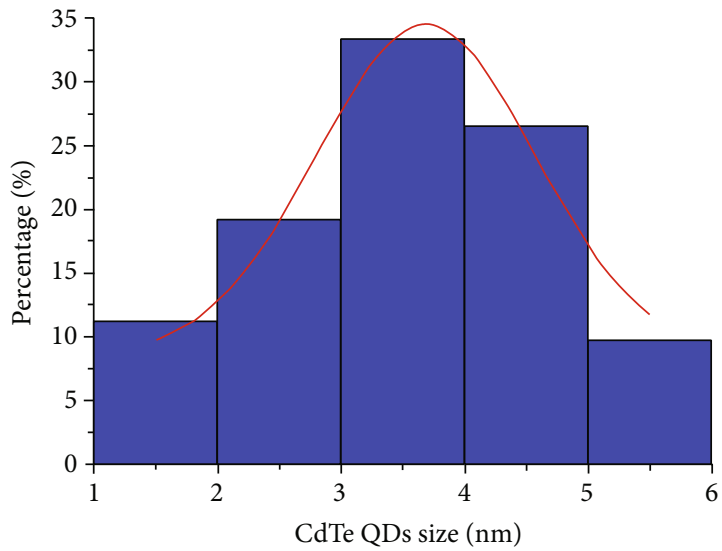

(c)

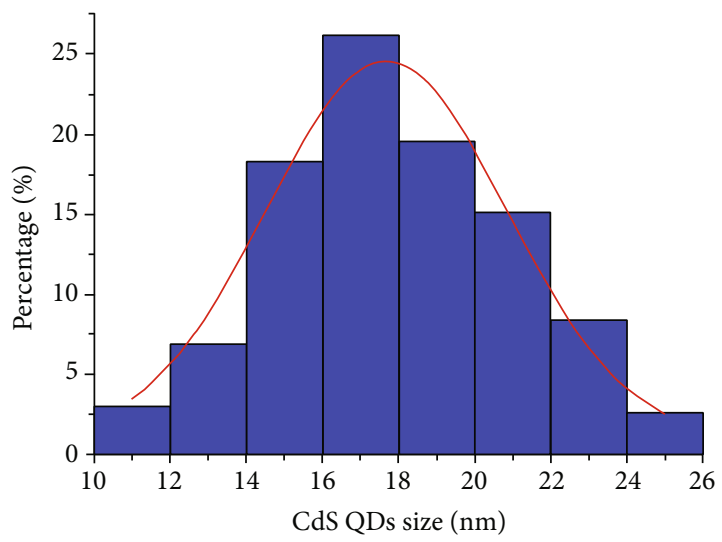

(e)

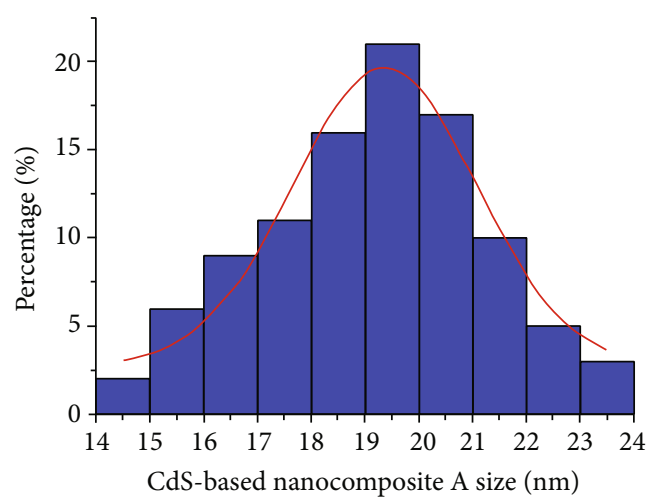

(b)

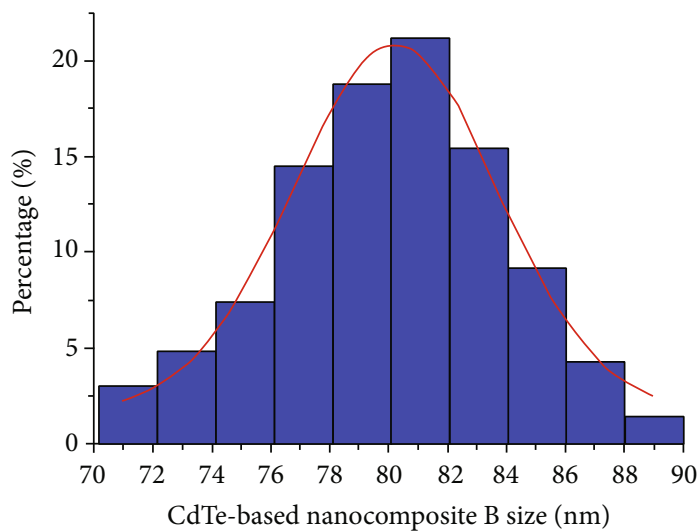

(d)

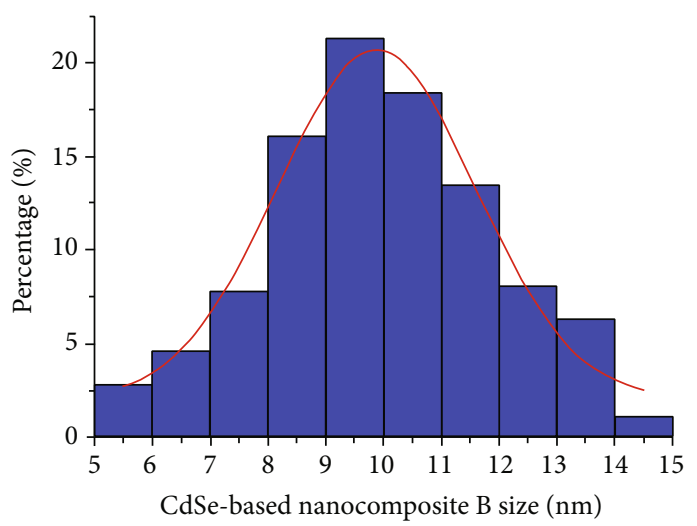

(f)

FIgURE 4: (a) Size distribution of CdS QDs; (b) size distribution of CdS- $\mathrm{TiO}_{2}$ nanocomposite sample (CdS-based nanocomposite A); (c) size distribution of CdTe QDs; (d) size distribution of $\mathrm{CdTe} / \mathrm{TiO}_{2}$ nanocomposite (CdTe-based nanocomposite $\mathrm{B}$ ); (e) size distribution of CdSe QDs; (f) size distribution of $\mathrm{CdSe}_{\mathrm{TiO}}$ nanocomposite (CdSe-based nanocomposite $\mathrm{B}$ ).

(220), and (311) of cubic crystal structure of CdTe, belonged to the sphalerite cubic phase.

As shown in Figure 5(c), the XRD diffraction peaks of the synthesized $\mathrm{CdSe} / \mathrm{TiO}_{2}$ nanocomposite (CdSe-based nanocomposite B) around $2 \theta$ of $25.27^{\circ}, 37.8^{\circ}, 56^{\circ}$, and $62^{\circ}$ could be indexed to the characteristic peaks (101), (004), (211), and (204) of anatase $\mathrm{TiO}_{2}$. It was calculated that the average crystallite sizes are $21.5 \mathrm{~nm}$ for pure $\mathrm{TiO}_{2}, 17.5 \mathrm{~nm}$ for CdSe, and $10.6 \mathrm{~nm}$ for $\mathrm{CdSe} / \mathrm{TiO}_{2}$ nanocomposite. The data obtained by TEM analysis of $\mathrm{CdSe}$ and $\mathrm{CdSe} / \mathrm{TiO}_{2}$ nanocomposite (Figure 3(f)) was consistent with it.

3.1.3. UV-Vis Spectroscopy. The nanoparticles were investigated by their UV-Vis absorption spectra.

As shown in Figure 6(a), the absorption thresholds were 387.5, 480, 491, 495, and $507 \mathrm{~nm}$ for the $\mathrm{TiO}_{2}, \mathrm{CdS}-\mathrm{TiO}_{2}$ samples 1.0, 0.6, 0.4, and 0.2 (CdS-based nanocomposite A), respectively. It indicated that the absorption spectra of 


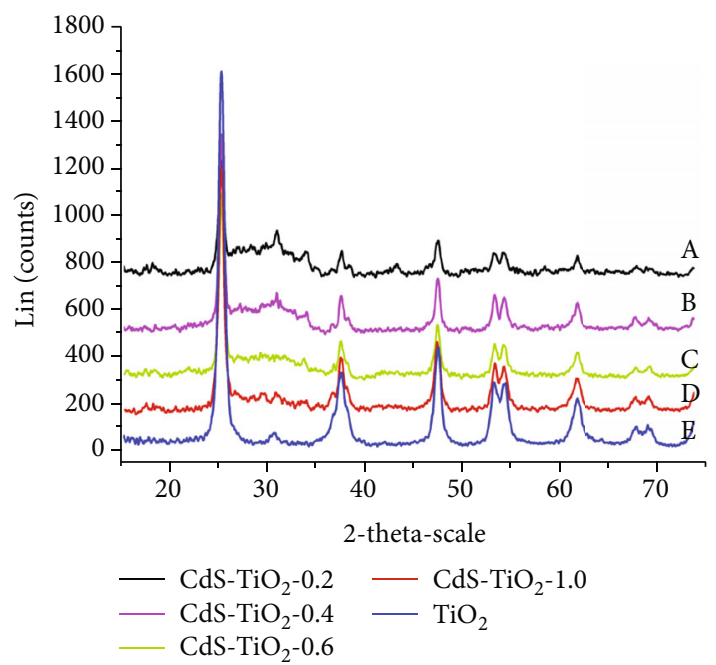

(a)

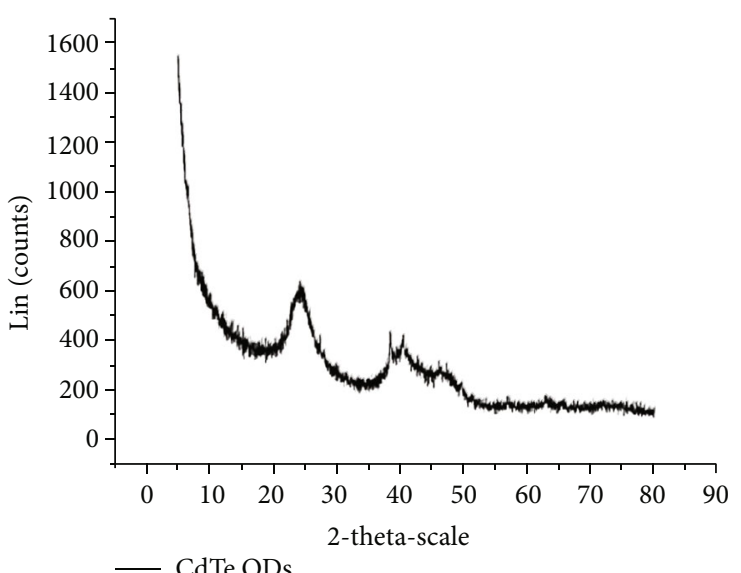

(b)

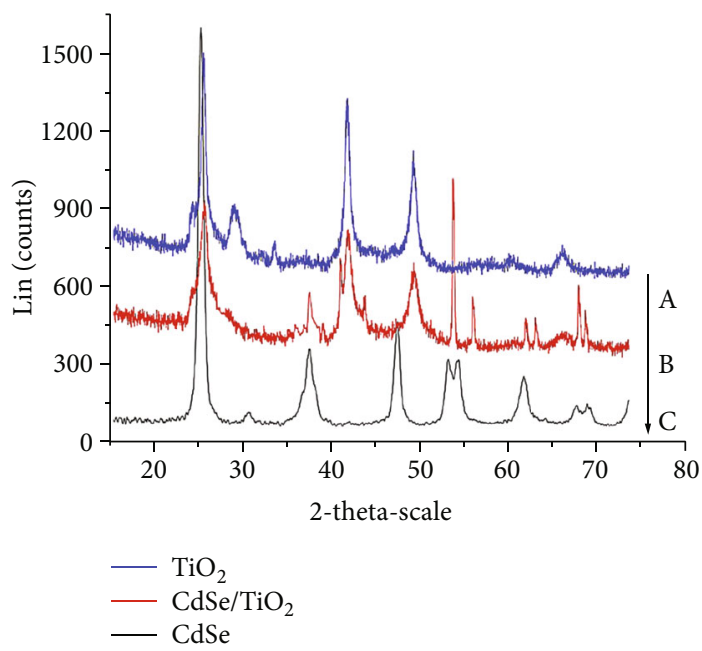

(c)

Figure 5: (a) The XRD patterns of $\mathrm{TiO}_{2}$ and $\mathrm{CdS}-\mathrm{TiO}_{2}$ nanocomposites (CdS-based nanocomposite A); (b) the XRD pattern of CdTe quantum dots (CdTe-based nanocomposite A); (c) the XRD patterns of $\mathrm{CdSe}, \mathrm{TiO}_{2}$, and $\mathrm{CdSe} / \mathrm{TiO}{ }_{2}$ nanocomposite (CdSe-based nanocomposite $\mathrm{B})$.

CdS- $\mathrm{TiO}_{2}$ samples were red-shifted to the visible region in varying degrees compared with pure $\mathrm{TiO}_{2}$. According to the formula [44]:

$$
\lambda=\frac{1240}{E_{g}},
$$

the band gap energy was $3.2,2.58,2.52,2.50$, and $2.45 \mathrm{eV}$ for the $\mathrm{TiO}_{2}, \mathrm{CdS}-\mathrm{TiO}_{2}$ samples $1.0,0.6,0.4$, and 0.2 , respectively. The results showed that the presence of CdS would narrow the band gap of nanoparticles, enhance the absorption of visible light, and result in the absorption spectrum of nanoparticles to red shift.

As shown in Figure 6(b), the absorption peak of CdTe was at $460 \mathrm{~nm}$. The absorption spectrum range corresponded to $\mathrm{CdTe} / \mathrm{TiO}_{2}$ nanocomposite (CdTe-based nanocomposite B) was expanded to the visible region. The results showed that the presence of CdTe QDs in CdTe/ $\mathrm{TiO}_{2}$ enhanced the absorption of visible light and caused the red shift of the absorption spectrum of $\mathrm{TiO}_{2}$.

The absorption spectra of hydroxyacetic acid-coated CdTe (CdTe-based nanocomposite C) and CdSe (CdSebased nanocomposite A) QDs are shown in Figure 6(c). The absorption wavelength of the two kinds of QDs was concentrated in the range of from 400 to $500 \mathrm{~nm}$. In this band, the absorption of CdSe QDs was obviously greater than CdTe.

As shown in Figure 6(d), the absorption thresholds were 387.5, 415, 444, 487, and $637 \mathrm{~nm}$ for the pure $\mathrm{TiO}_{2}$, CdSe/ $\mathrm{TiO}_{2}$ samples $0.5,1$, and 2 (CdSe-based nanocomposite $\mathrm{B}$ ) and $\mathrm{CdSe}$, respectively. It indicated that the absorption spectra of $\mathrm{CdSe} / \mathrm{TiO}_{2}$ samples were red-shifted to the visible region in varying degrees compared with pure $\mathrm{TiO}_{2}$. According to the above formula (2), the band gap energy was 3.2, 2.99, 2.79, 2.55, and $1.95 \mathrm{eV}$ for the pure $\mathrm{TiO}_{2}, \mathrm{CdSe} / \mathrm{TiO}_{2}$ samples 0.5, 


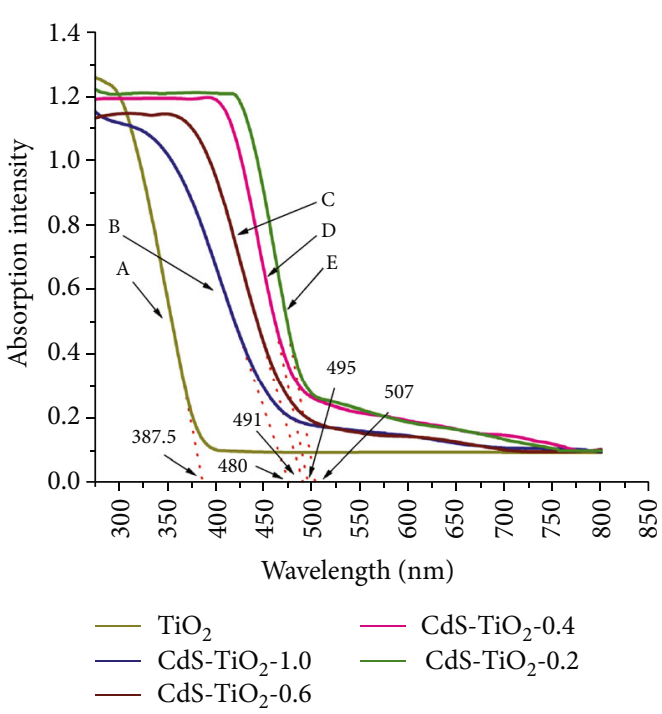

(a)

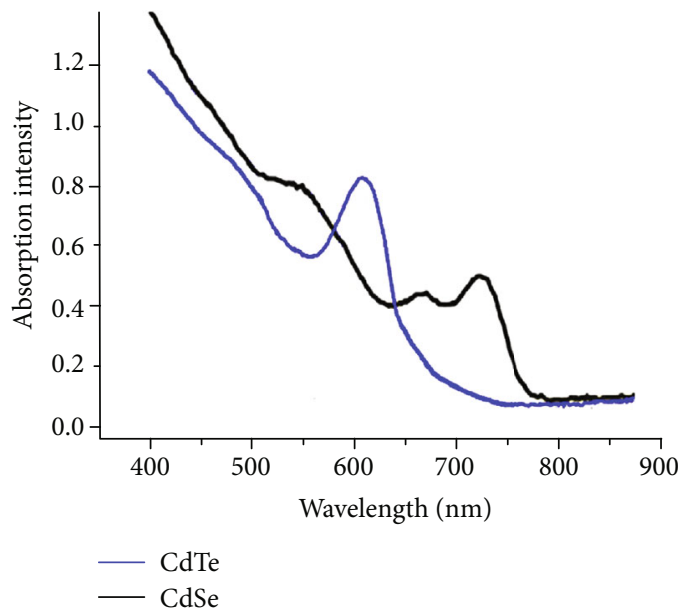

(c)

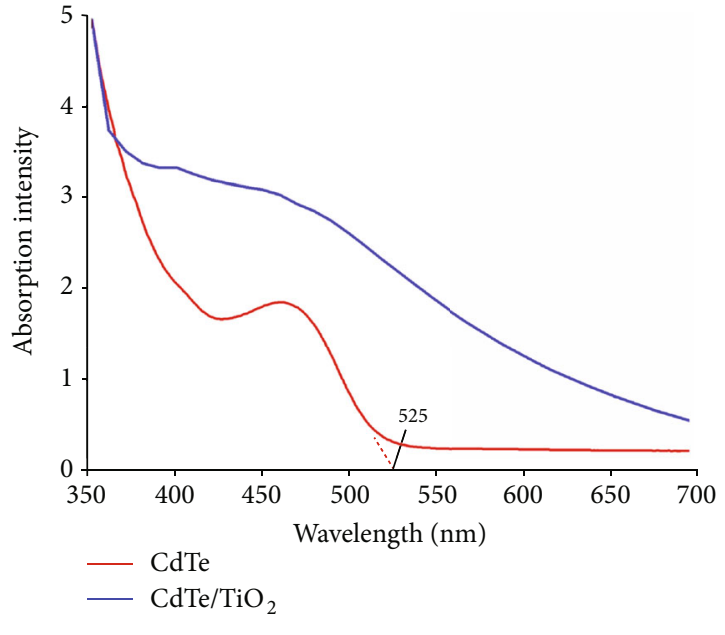

(b)

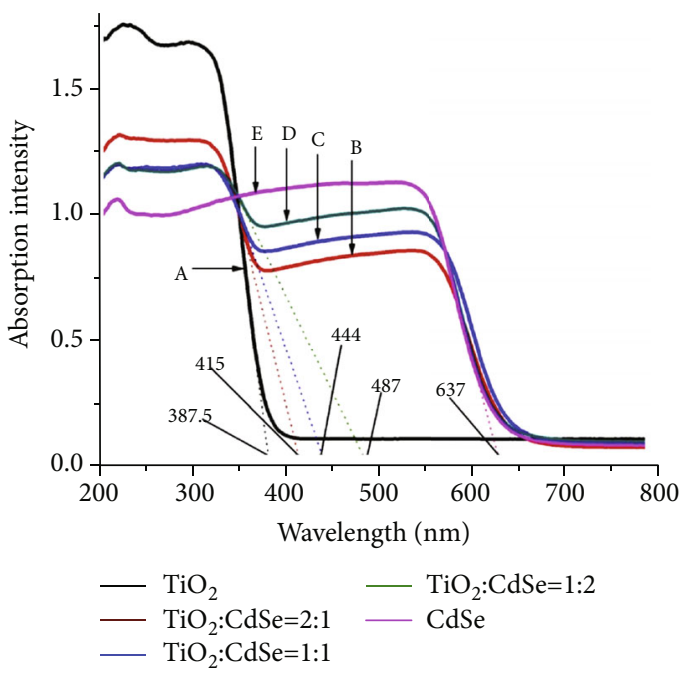

(d)

FIgure 6: (a) The UV-Vis absorption spectra of pure $\mathrm{TiO}_{2}$ and CdS-based nanocomposite A. (b) The UV-Vis absorption spectra of CdTe and CdTe-based nanocomposite B. (c) The UV-Vis absorption spectra of hydroxyacetic acid-coated CdTe QDs (CdTe-based nanocomposite C) and CdSe QDs (CdSe-based nanocomposite A). (d) The UV-Vis absorption spectra of pure $\mathrm{TiO}_{2}$, CdSe, and CdSebased nanocomposite $\mathrm{B}$.

1, and 2 and CdSe, respectively. The result showed that the presence of CdSe would narrow the band gap of nanoparticles, enhance the absorption of visible light, and result in the absorption spectrum of nanoparticles to red shift.

3.1.4. FS Analysis. Combination of holes and photogenerated electrons on the surface of semiconductor nanoparticles and the efficiency of photocatalytic activity can be demonstrated by FS. The lower the photoluminescence intensity, the lower the recombination rate of photoinduced electron-hole pairs, and the higher the photocatalytic activity of semiconductor photocatalyst. The reactive oxygen species will be produced through the reaction of the hole and the substance in the solution, and it will inactivate the cells. Therefore, the number of oxygen holes on the surface of $\mathrm{TiO}_{2}$ determines the intensity of its photocatalytic activity [45].
As shown in Figure 7(a), it showed the fluorescence emission spectra of $\mathrm{TiO}_{2}$ and $\mathrm{CdS}-\mathrm{TiO}_{2}$ nanocomposite, and the hole electron recombination rate on the $\mathrm{TiO}_{2}$ surface was analyzed. The fluorescence intensity of $\mathrm{TiO}_{2}$ changed significantly after the doping of CdS QDs. Compared with pure $\mathrm{TiO}_{2}$, the fluorescence emission intensity of $\mathrm{CdS}-\mathrm{TiO}_{2}$ samples $0.6,0.4$, and 1.0 decreased significantly, while the fluorescence intensity of sample 0.2 increased. Due to that, the emission fluorescence of semiconductor nanoparticles mainly depended on the combination of photogenerated holes and electrons. Therefore, it could be analyzed that effective electron transfer occurs between CdS QDs and $\mathrm{TiO}_{2}$ shell of samples 0.6, 0.4, and 1.0, and the recombination rate of holes and electrons was significantly reduced under $410 \mathrm{~nm}$ irradiation. The fluorescence intensity of sample 0.6 was the most strongly weakened, 


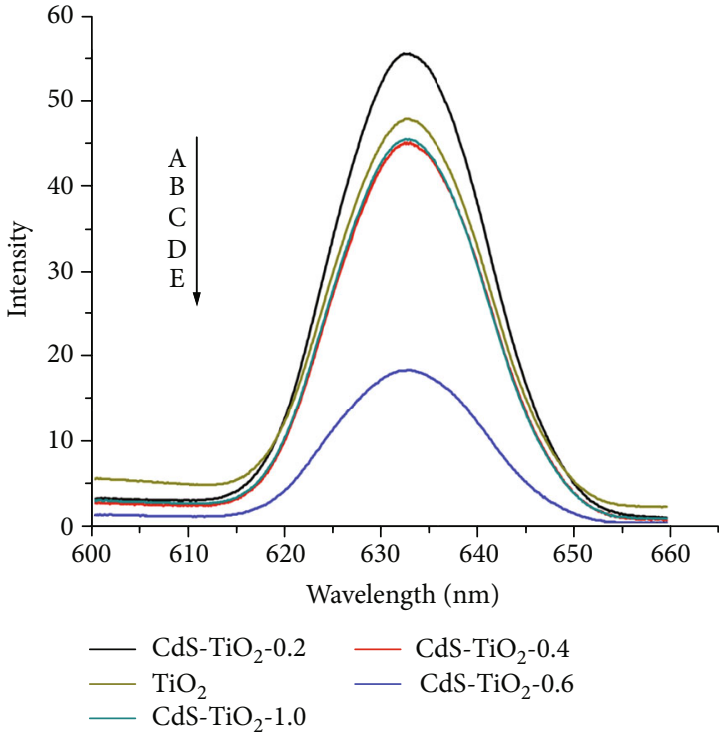

(a)

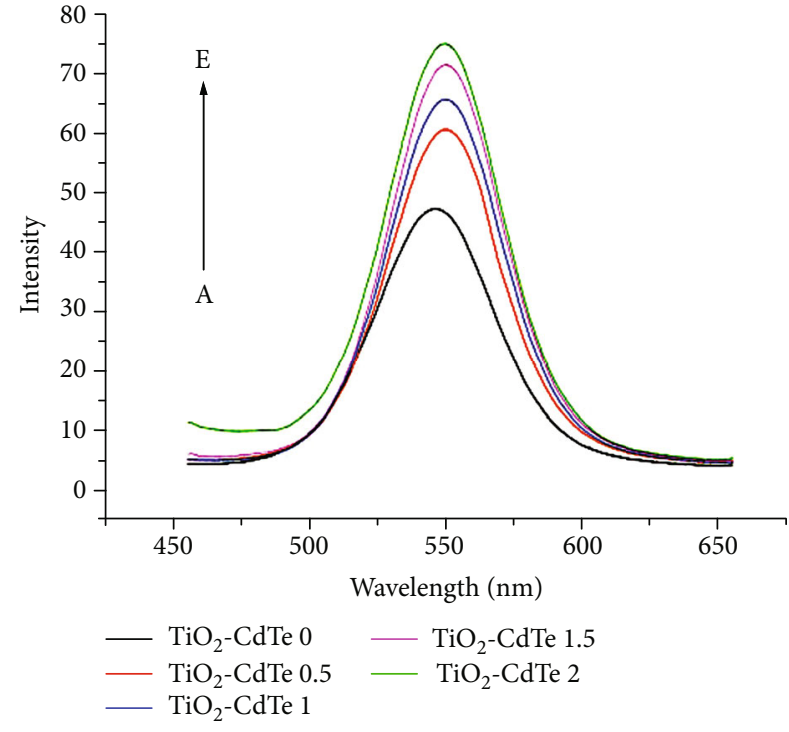

(b)

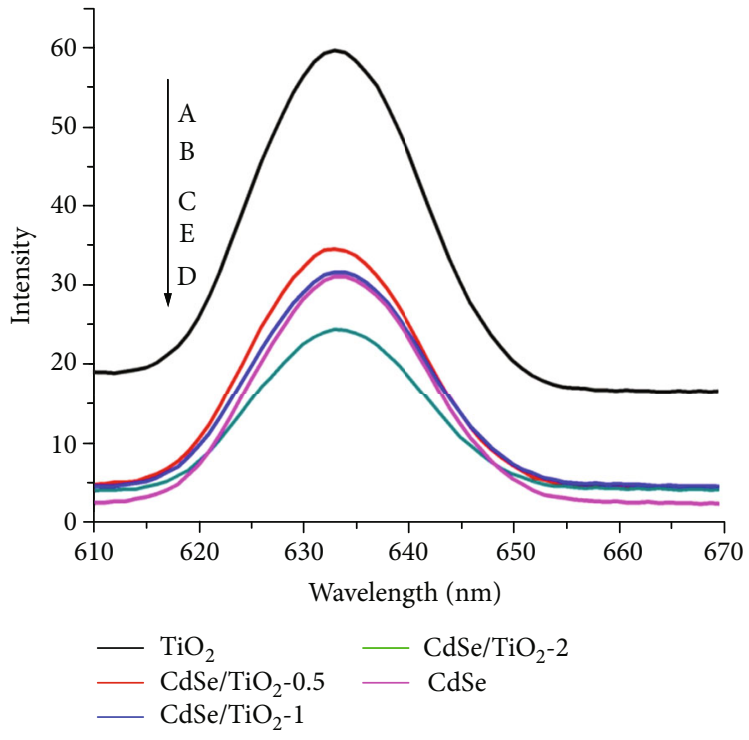

(c)

Figure 7: (a) The fluorescence emission spectrum of $\mathrm{TiO}_{2}$ and CdS-based nanocomposite $\mathrm{A}$ with the excitation wavelength of $410 \mathrm{~nm}$. (b) The fluorescence spectra of CdTe with the excitation wavelength of $345 \mathrm{~nm}$. CdTe-based nanocomposite A $\left(\mathrm{CdTe:} 25 \mu \mathrm{g} / \mathrm{mL} ; \mathrm{TiO}{ }_{2}(\mathrm{~A}-\mathrm{E})\right.$ : $0 \mu \mathrm{g} / \mathrm{mL}, 0.5 \mu \mathrm{g} / \mathrm{mL}, 1 \mu \mathrm{g} / \mathrm{mL}, 1.5 \mu \mathrm{g} / \mathrm{mL}$, and $2 \mu \mathrm{g} / \mathrm{mL}$ ). (c) The fluorescence spectra of pure $\mathrm{TiO}_{2}$, CdSe, and CdSe-based nanocomposite B with the excitation wavelength of $410 \mathrm{~nm}$.

indicating that the inhibition of hole electron recombination was the most prominent. However, the fluorescence emission of sample 0.2 was enhanced which might be due to the high content of CdS which led to a lot of CdS QD aggregation on the surface of $\mathrm{TiO}_{2}$ and reduced the number of oxygen holes.

As shown in Figure 7(b), the emission wavelength of CdTe was about from 500 to $600 \mathrm{~nm}$ when the excitation wavelength was $345 \mathrm{~nm}$. While the concentration of CdTe was constant, the concentration of $\mathrm{TiO}_{2}$ increased, and the fluorescence emission peak intensity of CdTe increased gradually. This indicated that $\mathrm{CdTe}$ could reduce the recombination of hole and electron on the surface of $\mathrm{TiO}_{2}$.
As shown in Figure 7(c), the fluorescence intensity of $\mathrm{CdSe} / \mathrm{TiO}_{2}$ nanocomposite was significantly lower than that of pure $\mathrm{TiO}_{2}$, and the fluorescence intensity of sample CdSe/ $\mathrm{TiO}_{2}-2$ was the weakest. The doping of CdSe QDs changed the efficiency of capture, migration, and transformation of the nanocomposite, reduced the recombination rate of electrons and holes, and improved the separation efficiency of photogenerated carriers, and photocatalytic activity.

3.2. Cytotoxicity of $C d X \quad(X=S, \quad T e, \quad S e)$-Based Nanocomposites on HL60 Cells. The low dark toxicity is one of the important characteristics of a photosensitizer. The cell activity was detected by the CCK- 8 method. The 


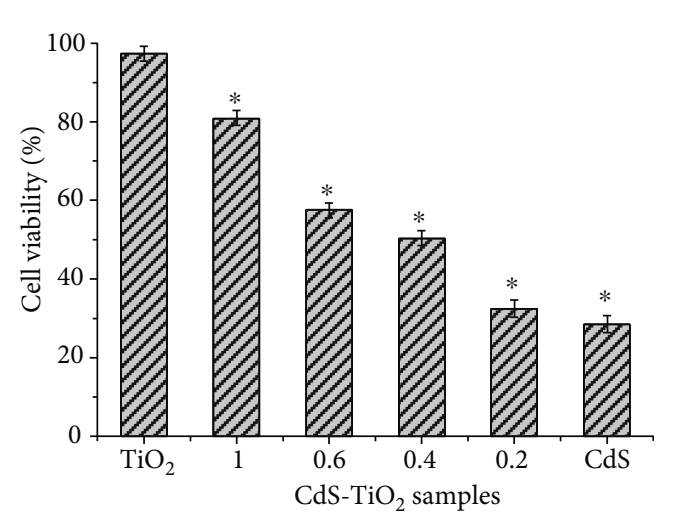

(a)

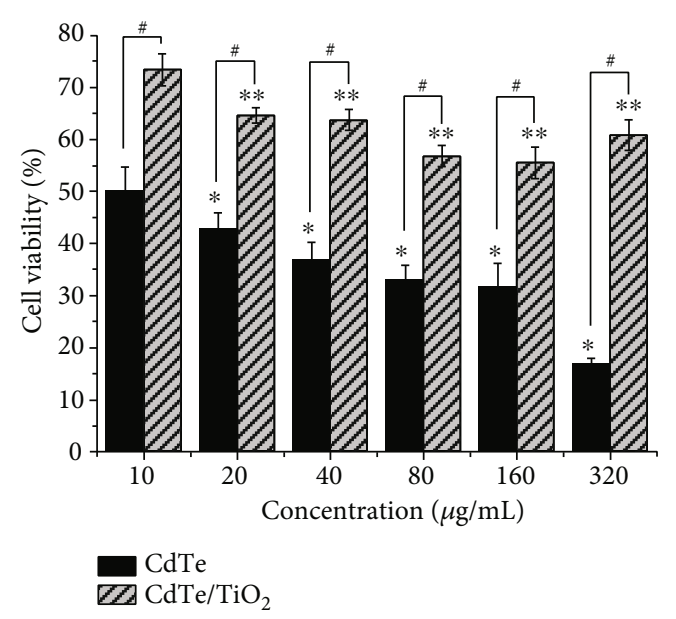

(b)

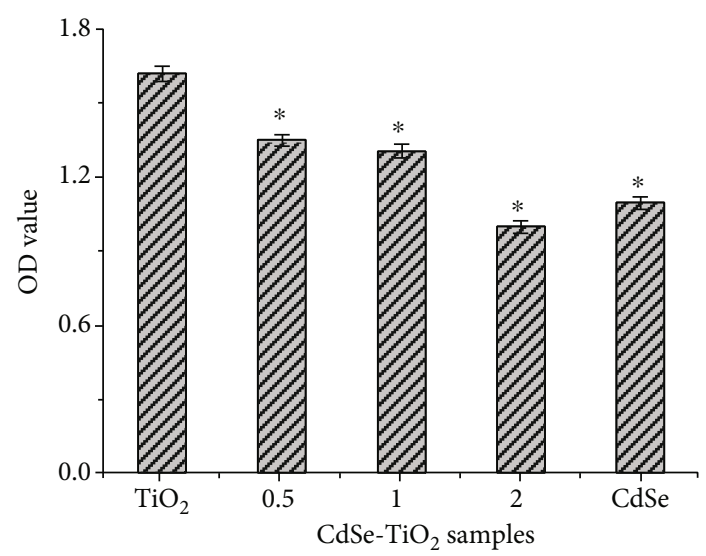

(c)

FIGURE 8: (a) Viability of cells treated with CdS-based nanocomposite A in different shell thickness at the concentration of $20 \mu \mathrm{g} / \mathrm{mL}$. The without radiation group was kept in dark condition for 24 hours. Each data point represents mean $\pm \operatorname{SD}(n=3)$. $t$-test was performed on the data of the $\mathrm{TiO}_{2}$ group and the different sample group. ${ }^{*} \mathrm{P}<0.05$ indicated that there was a difference compared with groups of TiO without irradiation. (b) The effects of relative survival of HL60 cells coincubated with CdTe and CdTe-based nanocomposite B for 24 hours in the dark. Each data point represents mean \pm SD $(n=3)$. $t$-test was performed on the data of the CdTe group and the CdTe/ $\mathrm{TiO}_{2}$ group. ${ }^{*} P<0.05$ indicated that there was a difference compared with groups of CdTe in different concentrations, ${ }^{* *} P<0.05$ indicated that there was a difference compared with groups of $\mathrm{CdTe} / \mathrm{TiO}{ }_{2}$ in different concentrations, and ${ }^{\#} P<0.001$ indicated that there was a difference that $\mathrm{CdTe}$ compared with $\mathrm{CdTe} / \mathrm{TiO}_{2}$ in the same concentration. (c) Viability of HL60 cells treated with $\mathrm{CdSe}$, TiO , and CdSe-based nanocomposite B with different doping ratios at the concentration of $4 \mu \mathrm{g} / \mathrm{mL}$. The without irradiation group was kept in dark condition for 24 hours. Each data point represents mean $\pm \mathrm{SD}(n=3) . t$-test was performed on the data of the TiO ${ }_{2}$ group and the different sample group. ${ }^{*} P<0.05$ indicated that there was a difference compared with groups of $\mathrm{TiO}_{2}$ without irradiation. All the data shown in the figure are representative.

OD values of the treatment group (treatment with nanocomposites for one day) and the control group (without treatment with nanoparticles) were measured by the Model 680 Microplate Reader. The cell viability was calculated as follows:

$$
R(\%)=\left(\frac{\mathrm{OD}_{\text {treat }}}{\mathrm{OD}_{\text {control }}}\right) \cdot 100 \%
$$

where the $\mathrm{OD}_{\text {treat }}$ and $\mathrm{OD}_{\text {control }}$ are the mean absorption values at $490 \mathrm{~nm}$ for the treatment and control group, respectively.
Studies have shown that the injection concentration of nanoparticles for mouse experiments is from 0 to $350 \mu \mathrm{g} /$ $\mathrm{mL}$ [46-48]. Therefore, we choose the experiment concentration from 0.2 to $320 \mu \mathrm{g} / \mathrm{mL}$ as a reference and that conforms to toxicological value.

The effect of $\mathrm{CdS}-\mathrm{TiO}_{2}$ nanocomposites (CdS-based nanocomposite A) with different thickness of $\mathrm{TiO}_{2}$ shell on HL60 cell activity in dark is shown in Figure 8(a). As can be seen from the figure, cell survival rates of treatment with CdS and CdS- $\mathrm{TiO}_{2}$ groups $0.2,0.4,0.6$, and 1.0 and $\mathrm{TiO}_{2}$ were $28.5 \%, 32.4 \%, 50.4 \%, 57 \%, 80 \%$, and $97 \%$, respectively, under the dark condition. The lowest survival rate of cells treated with CdS was $28.5 \%$ confirmed that the high biotoxicity of CdS QDs. Compared with the group of treatment 
with CdS QDs, the cell survival rate of the group of treatment with $\mathrm{CdS}-\mathrm{TiO}_{2}$ increased with the increase of the thickness of the $\mathrm{TiO}_{2}$ shell. In the dark condition group corresponding to $\mathrm{CdS}-\mathrm{TiO}_{2}$ sample 1.0 , the cell survival rate reached the highest $80 \%$. These results indicated that it could significantly protect the cells under dark condition in the presence of $\mathrm{TiO}_{2}$ shell and reduced the dark toxicity of CdS QDs. For CdS QDs, the release of $\mathrm{Cd}^{2+}$ was the main toxic mechanism [49]. The experimental results showed that the existence of $\mathrm{TiO}_{2}$ shell could effectively protect the semiconductor QDs in solution and prevent corrosion [50]. In the dark toxicity test of this experiment, the existence of $\mathrm{TiO}_{2}$ shell could effectively reduce the biological toxicity of CdS QDs by blocking their contact with the solution.

HL60 cells were treated with different concentrations of CdTe QDs and $\mathrm{CdTe} / \mathrm{TiO}_{2}$ nanocomposite (CdTe-based nanocomposite $\mathrm{B}$ ); the relation between concentration and relative survival rate of cells is shown in Figure 8(b). When the concentration of $\mathrm{CdTe} / \mathrm{TiO}_{2}$ nanocomposite was lower than $20 \mu \mathrm{g} / \mathrm{mL}$, the cytotoxicity was relatively lower. When the concentration was higher than $160 \mu \mathrm{g} / \mathrm{mL}$, the cytotoxicity was relatively weakened. When the concentration was $80 \mu \mathrm{g} / \mathrm{mL}$, the cytotoxicity to HL60 cells was the highest. It indicated that the cell uptake of nanoparticles had reached saturation in the concentration of $80 \mu \mathrm{g} / \mathrm{mL}$. The dark toxicity of $\mathrm{CdTe} / \mathrm{TiO}_{2}$ was lower than that of CdTe QDs.

The effect of $\mathrm{CdSe} / \mathrm{TiO}_{2}$ nanocomposite (CdSe-based nanocomposite $\mathrm{B}$ ) with different doping ratios of $\mathrm{TiO}_{2}$ and CdSe on the activity of HL60 cells without irradiation is shown in Figure 8(c). When the concentration of nanoparticles was $4 \mu \mathrm{g} / \mathrm{mL}$, the higher the doping ratio of CdSe and $\mathrm{TiO}_{2}$, the lower the cell activity, and the dark toxicity of $\mathrm{CdSe} / \mathrm{TiO}_{2}$ with a doping ratio of two was the highest. The dark toxicity of $\mathrm{CdSe} / \mathrm{TiO}_{2}$ with a doping ratio of 0.5 and one was lower; it indicated that $\mathrm{CdSe} / \mathrm{TiO}_{2}$ nanocomposite had good biocompatibility.

3.3. Photodynamic Therapy of $C d X(X=S$, Te, Se)-Based Nanocomposites on HL60 Cells. The HL60 cells in the logarithmic growth phase were inoculated into two 96-well plates marked with A and B. Plate A was incubated for 12 hours without irradiation, next exposed to visible light for one hour, then incubated for 12 hours without irradiation. Plate B was incubated for 24 hours in the incubator without irradiation. Photodynamic inactivation efficiency (indicated by $\mathrm{PDT}_{\text {efficiency }}$ ) was expressed by cell viability (OD value), which was calculated as follows:

$$
\mathrm{PDT}_{\text {efficiency }}=1-\frac{\mathrm{OD}_{\mathrm{Ir}}}{\mathrm{OD}_{\text {Non-Ir }}} \cdot 100 \% \text {, }
$$

where the $\mathrm{OD}_{\mathrm{Ir}}$ and $\mathrm{OD}_{\mathrm{Non}-\mathrm{Ir}}$ were the mean absorption values at $490 \mathrm{~nm}$ for the irradiation and no irradiation, respectively.

In Figure 9(a), compared with the without radiation group, the cell activity of the $\mathrm{CdS}-\mathrm{TiO}_{2}$ treatment group decreased significantly with radiation. The PDT inactivation efficiency of $\mathrm{CdS} / \mathrm{TiO}_{2}$ nanocomposite sample 0.6 reached the highest $95 \%$. Even for the sample 1.0 with the lowest CdS con- tent, the PDT inactivation efficiency reached 60\%. These results indicated that the inactivation effect of $\mathrm{CdS}-\mathrm{TiO}_{2}$ nanocomposite (CdS-based nanocomposite A) on HL60 cells under irradiation was significantly enhanced due to the presence of CdS. Appropriate CdS QDs and $\mathrm{TiO}_{2}$ coating can reduce dark toxicity and increase PDT efficiency.

Figure 9(b) shows the OD values of cells treated with different concentrations of $\mathrm{TiO}_{2}-\mathrm{CdTe}$ (CdTe-based nanocomposite A) and cultured under irradiation and without irradiation, respectively. According to the above formula (4), the figure showed the PDT inactivation efficiency change tendency of $\mathrm{TiO}_{2}-\mathrm{CdTe}$ mixed system with $\mathrm{CdTe}$ concentration of $0.25,0.5,0.75$, and $1 \mu \mathrm{g} / \mathrm{mL}$ was $59.70 \%, 53.75 \%, 59.02 \%$, and $71.54 \%$, respectively. It indicated that the higher the CdTe concentration, the higher PDT efficiency and the lower dark toxicity in the low concentration range.

As shown in Figure 9(c), the relative survival rate of HL60 cells in the irradiation group treated with different concentrations of $\mathrm{CdTe} / \mathrm{TiO}_{2}$ nanocomposite (CdTe-based nanocomposite B) was significantly lower than that in the nonirradiation group. With the increasing concentration of $\mathrm{CdTe} / \mathrm{TiO}_{2}$ nanocomposite, the relative survival rate of HL60 cells decreased and showed a slowing trend after PDT. It indicated that PDT improved the inactivation efficiency of $\mathrm{CdTe} / \mathrm{TiO}_{2}$ nanocomposite on HL60 cells. In order to further explore the influence on PDT efficiency between the concentration of nanocomposite and irradiation time, the cells were irradiated with light at the dose of $18 \mathrm{~J} / \mathrm{cm}^{2}$ under the wavelength of $410 \mathrm{~nm}$ for 20,40 , and 60 minutes, respectively (Figure $9(\mathrm{~d})$ ). With the increase of irradiation time, the efficiency of PDT increased. Compared with the $\mathrm{TiO}_{2}$ nanoparticle group, the PDT efficiency of the CdTe/ $\mathrm{TiO}_{2}$ nanocomposite group was significantly improved and showed an increasing trend with the increase of concentration. The experimental result showed that when the concentration of $\mathrm{CdTe} / \mathrm{TiO}_{2}$ nanocomposite was $320 \mu \mathrm{g} / \mathrm{mL}$, the PDT efficiency reached the highest $87.7 \%$. The photocatalytic activity of $\mathrm{TiO}_{2}$ was enhanced by doping CdTe QDs under irradiation, which enhanced the PDT efficiency. However, when the concentration of $\mathrm{CdTe} / \mathrm{TiO}_{2}$ was higher than $80 \mu \mathrm{g} / \mathrm{mL}$, the PDT efficiency did not increase significantly. The concentration of cell exposure has reached absorption saturation.

As shown in Figure 9(e), the PDT efficiency of the hydroxyacetic acid-coated CdTe QDs (CdTe-based nanocomposite C) and CdSe QDs (CdSe-based nanocomposite A) concentration of $1.0,1.5,2.0$, and $2.5 \mu \mathrm{mol} / \mathrm{L}$, respectively, under the optimal light dosage parameters (CdTe of $15 \mathrm{~J} / \mathrm{cm}^{2}$ and CdSe of $18 \mathrm{~J} / \mathrm{cm}^{2}$ ) was shown. The inactivation efficiency of CdSe QDs was obviously higher than that of CdTe QDs. The PDT efficiency change tendency is shown in Figure 9(f), when the optimal concentration of both CdTe and CdSe QDs was $2.0 \mu \mathrm{mol} / \mathrm{L}$, and the light dosages were $12,15,18$, and $21 \mathrm{~J} / \mathrm{cm}^{2}$, respectively. Under the optimal light dosage parameters of $15 \mathrm{~J} / \mathrm{cm}^{2}$, the PDT inactivation efficiency of CdTe QDs with the concentration of $2.0 \mu \mathrm{mol} /$ L on HL60 cells was $62.7 \%$. Under the optimal light dosage of $18 \mathrm{~J} / \mathrm{cm}^{2}$, the PDT inactivation efficiency of HL60 cells with concentration of $2.0 \mu \mathrm{mol} / \mathrm{L} \mathrm{CdSe}$ QDs was $83.0 \%$. 


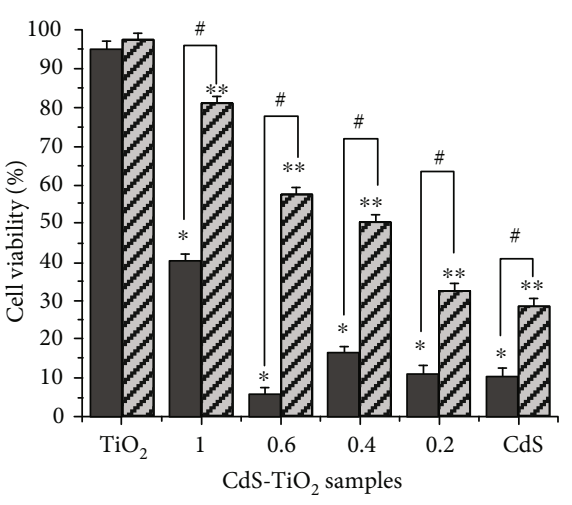

Radiation

D] Without radiation

(a)

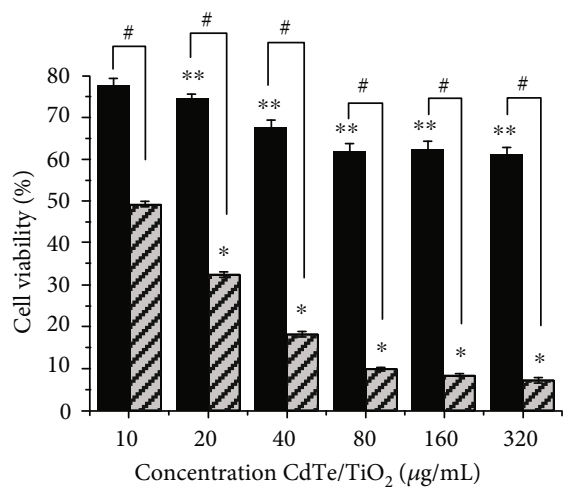

Non-irradiation

D/ Irradiation

(c)

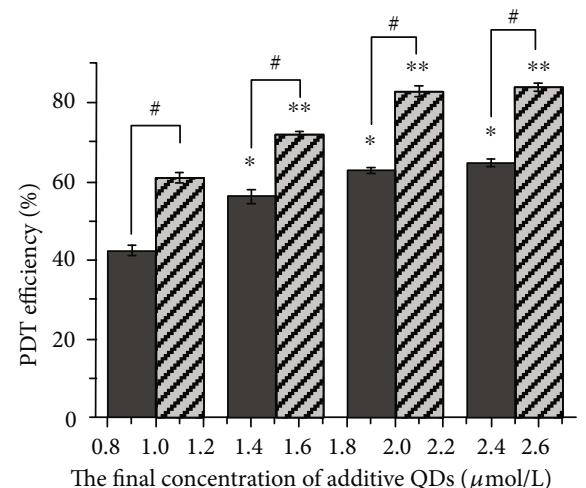

$\mathrm{CdTe}$

WC CdSe

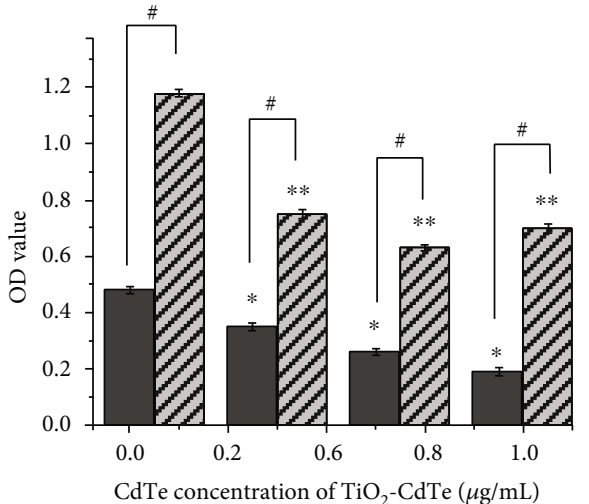

Radiation

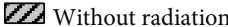

(b)

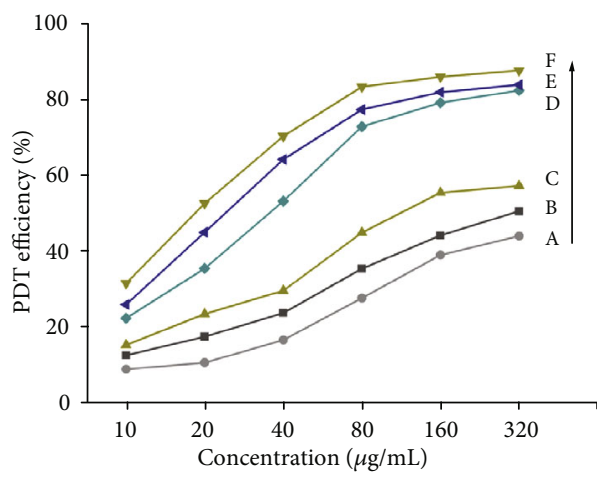

$\rightarrow \mathrm{TiO}_{2} 20 \mathrm{~min} \rightarrow \mathrm{CdTe} / \mathrm{TiO}_{2} 20 \mathrm{~min}$

$\rightarrow \mathrm{TiO}_{2} 40 \mathrm{~min} \leftarrow \mathrm{CdTe} / \mathrm{TiO}_{2} 40 \mathrm{~min}$

$\neg \mathrm{TiO}_{2} 60 \mathrm{~min} \longrightarrow \mathrm{CdTe}_{\mathrm{TiO}} 60 \mathrm{~min}$

(d)

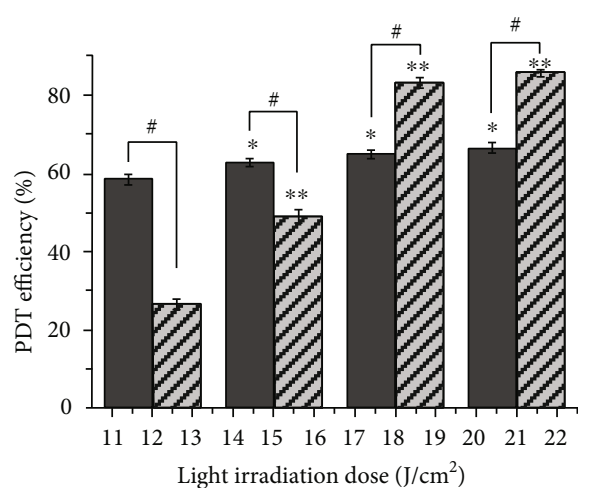

$\square \mathrm{CdTe}$

DC CdSe

(e)

FIgure 9: Continued. 


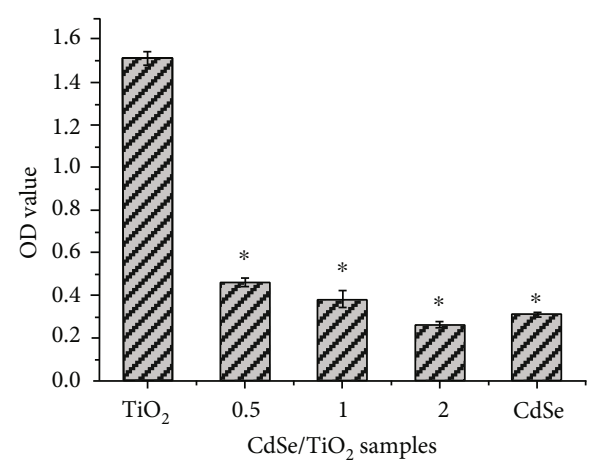

(g)

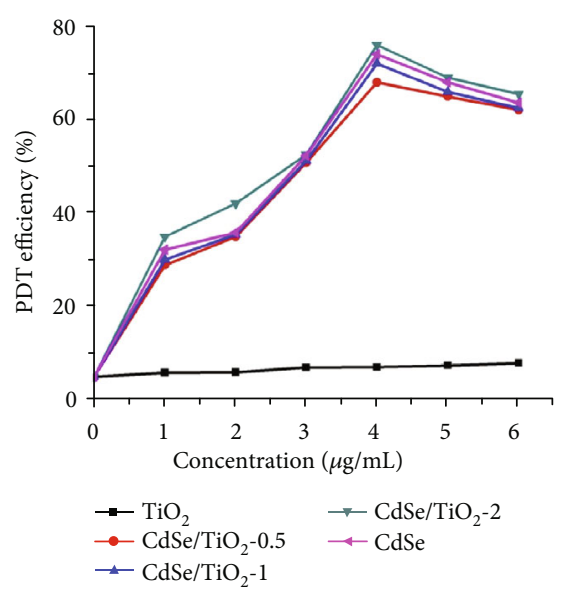

(h)

FIgURE 9: (a) Viability of cells treated with CdS-based nanocomposite A in different shell thickness at the concentration of $20 \mu \mathrm{g} / \mathrm{mL}$. The group of irradiation was under $410 \mathrm{~nm}$ light exposure for 1 hour with a power density of $18 \mathrm{~J} / \mathrm{cm}^{2}$. The without irradiation group was kept in dark condition for 24 hours. $t$-test was performed on the data of the irradiation group and the nonirradiation group. Each data point represents mean $\pm \mathrm{SD}(n=3)$. ${ }^{*} P<0.001$ indicated that there was a difference compared with groups of $\mathrm{TiO}_{2}$ with irradiation, ${ }^{* *} P<$ 0.001 indicated that there was a difference compared with groups of $\mathrm{TiO}_{2}$ without irradiation, and ${ }^{\#} P<0.05$ compared with the two groups. (b) The influence of different CdTe concentrations of CdTe-based nanocomposite A to OD values of HL60 cells. Each data point represents mean $\pm \mathrm{SD}(n=3)$. $t$-test was performed on the data of the irradiation group and the nonirradiation group. ${ }^{*} P<0.001$ indicated that there was a difference compared with groups of irradiation in the different concentration, ${ }^{* *} P<0.001$ indicated that there was a difference compared with groups of without irradiation in the different concentration, and ${ }^{*} P<0.05$ indicated that there was a difference compared with two groups. (c) The effect of irradiation on the relative survival of HL60 cells with CdTe-based nanocomposite B. Each data point represents mean $\pm \mathrm{SD}(n=3)$. $t$-test was performed on the data of the irradiation group and the nonirradiation group. ${ }^{*} P<0.001$ indicated that there was a difference compared with groups of irradiation in the different concentration, ${ }^{* *} P<0.001$ indicated that there was a difference compared with groups of without irradiation in the different concentration, and ${ }^{\#} P<0.05$ indicated that there was a difference compared with two groups. (d) The PDT efficiency of $\mathrm{TiO}_{2}$ and $\mathrm{CdTe}$-based nanocomposite $\mathrm{B}$ on HL60 with different irradiation times. Each data point represents mean $\pm \mathrm{SD}(n=3)$. ${ }^{*} P<0.05$ compared with groups of $\mathrm{TiO}_{2}$. (e) The inactivation efficiency of hydroxyacetic acid-coated CdTe QDs (CdTe-based nanocomposite C) and CdSe QDs (CdSe-based nanocomposite A) under the best light dosage $\left(\mathrm{CdTe}: 15 \mathrm{~J} / \mathrm{cm}^{2}\right.$, CdSe: $\left.18 \mathrm{~J} / \mathrm{cm}^{2}\right)$. Each data point represents mean $\pm \mathrm{SD}(n=3) . t$-test was performed on the data of the CdTe group and the CdSe group. ${ }^{*} P<0.001$ indicated that there was a difference compared with groups of CdTe in different concentrations, ${ }^{* *} P<0.001$ indicated that there was a difference compared with groups of CdSe in different concentrations, and ${ }^{\#} P<0.05$ indicated that there was a difference that CdTe compared with CdSe in the same concentration. (f) The inactivation efficiency of CdTe-based nanocomposite C and CdSe-based nanocomposite A under the best QD concentration $(2.0 \mu \mathrm{mol} / \mathrm{L})$. Each data point represents mean $\pm \mathrm{SD}(n=3)$. $t$-test was performed on the data of the CdTe group and the CdSe group. ${ }^{*} P<0.001$ indicated that there was a difference compared with groups of CdTe in different light irradiation doses, ${ }^{* *} P<0.001$ indicated that there was a difference compared with groups of CdSe in different light irradiation doses, and ${ }^{\#} P<0.05$ indicated that there was a difference that CdTe compared with CdSe in the same light irradiation dose. (g) The viability of cells treated with $\mathrm{TiO}_{2}$, CdSe, and CdSe-based nanocomposite $\mathrm{B}$ at the concentration of $4 \mu \mathrm{g} / \mathrm{mL}$. The irradiation group was irradiated for 1 hour. Each data point represents mean \pm $\mathrm{SD}(n=3)$. $t$-test was performed on the data of the $\mathrm{CdSe} / \mathrm{TiO}_{2}$ group and the $\mathrm{TiO}_{2}$ group. ${ }^{*} \mathrm{P}<0.05$ compared with groups of $\mathrm{TiO}{ }_{2}$; $(\mathrm{h}$ ) the PDT efficiency of $\mathrm{TiO}_{2}$, CdSe, and CdSe-based nanocomposite B on HL60 cells at various concentrations. Each data point represents mean $\pm \mathrm{SD}(n=3)$. ${ }^{*} P<0.05$ compared with groups of $\mathrm{TiO}_{2}$. All the data shown in the figure are representative.

The inactivation efficiency of CdSe QDs was higher than that of CdTe QDs at different concentrations of QDs under optimal light dosage parameters. The inactivation efficiency of CdSe was significantly higher than that of CdTe under the optimal concentration of QDs and different light dosages. In conclusion, the PDT efficiency of CdSe QDs was superior to that of CdTe QDs.

$\mathrm{CdSe} / \mathrm{TiO}_{2}$ nanocomposite (CdSe-based nanocomposite B) in different ratios of $0.5,1$, and 2 with final concentration of $1,2,3,4,5$, and $6 \mu \mathrm{g} / \mathrm{mL}$, CdSe and $\mathrm{TiO}_{2}$ nanoparticle solutions were coincubated with HL60 cells for PDT experiment. The OD value of the irradiation group is shown in Figure $9(\mathrm{~g})$. Compared with the nonirradiation group (Figure $8(\mathrm{c})$ ), the OD value of cells treated with $\mathrm{CdSe} / \mathrm{TiO}_{2}$ nanocomposite under irradiation was significantly reduced. Besides, the OD value of cells treated with $\mathrm{CdSe} / \mathrm{TiO}_{2}$ nanocomposite was lower than that of pure $\mathrm{TiO}_{2}$. The PDT efficiency of various nanoparticles at different concentrations is shown in Figure 9(h). The inactivation efficiency of HL60 cells induced by $\mathrm{CdSe} / \mathrm{TiO}_{2}$ was significantly higher than that of pure $\mathrm{TiO}_{2}$. When the ratio of $\mathrm{CdSe}$ to $\mathrm{TiO}_{2}$ equaled two and the concentration was $4 \mu \mathrm{g} / \mathrm{mL}$, the PDT efficiency reached the highest $76 \%$. The experimental result showed that the inactivation efficiency of $\mathrm{CdSe} / \mathrm{TiO}_{2}$ nanocomposite on HL60 cells was significantly enhanced under irradiation.

3.4. Ultrastructural Morphology of the Treated Cells. The samples of HL60 cells were collected by critical point drying 


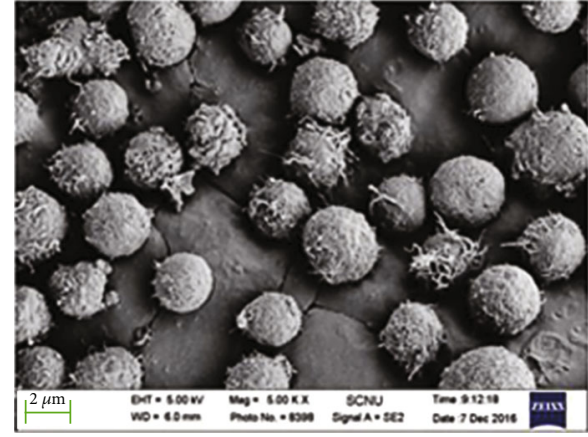

(a)

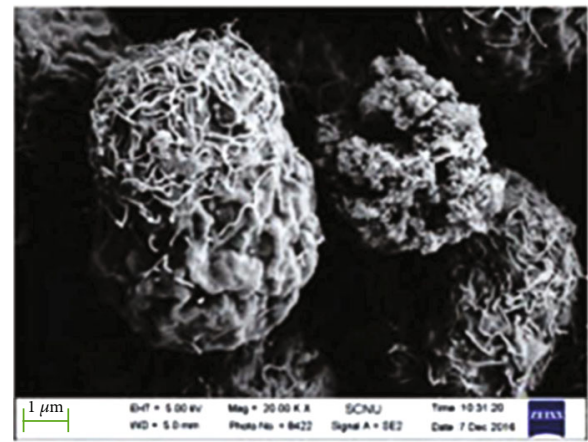

(c)

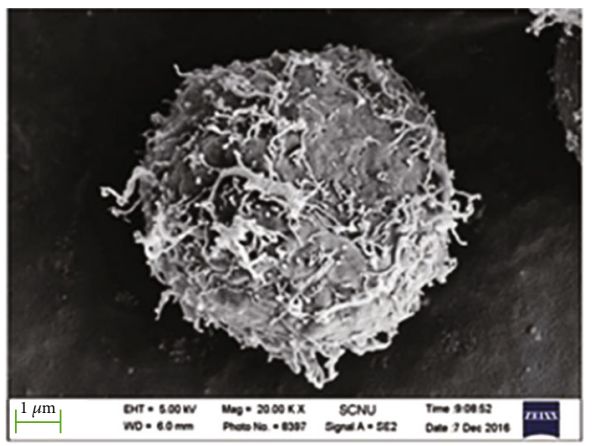

(b)

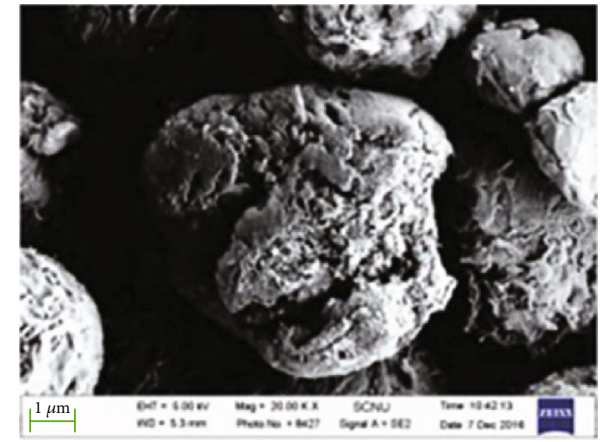

(d)

FIgURE 10: (a) The ultrastructural morphology of multiple normal HL60 cells; (b) the ultrastructural morphology of single normal HL60 cell; (c) the ultrastructural morphology of the HL60 cells after CdSe treatment; (d) the ultrastructural morphology of the HL60 cells after CdSe-based nanocomposite B treatment.

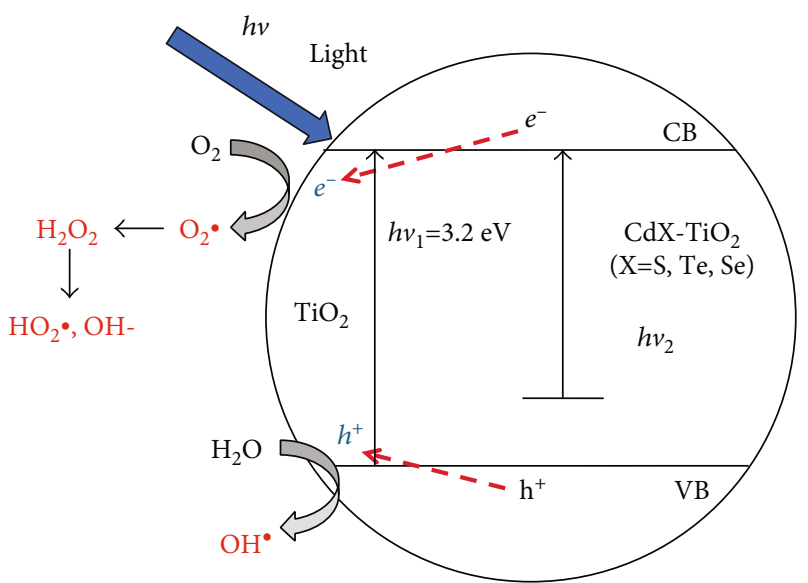

Figure 11: The possible mechanism of excitation and charge transfer process between $\mathrm{CdX}(\mathrm{X}=\mathrm{S}, \mathrm{Te}, \mathrm{Se})$ and $\mathrm{TiO}_{2}$ in the $\mathrm{CdX}(\mathrm{X}=\mathrm{S}, \mathrm{Te}, \mathrm{Se})$-based nanocomposites under irradiation.

method, which were normal HL60 cells in logarithmic growth phase and HL60 cells after PDT treatment, respectively. Firstly, the cells were fixed in $2.5 \%$ glutaraldehyde solution. Then, phosphate buffer solution (PBS) was used to rinse, and the upper layer of waste solution was discarded after centrifugation. It was dehydrated and fixed by gradient ethanol $(50 \%, 70 \%, 80 \%, 90 \%$ once, and $100 \%$ twice, 10 minutes each time). Finally, it was fixed with ethanol isodiester twice, each time for three minutes. The cell samples obtained by the above treatment were dried by a critical point dryer and then plated by a metal ion sputtering device and observed under a Zeiss Ultra-55 scanning electron microscope.

As shown in Figures 10(a) and 10(b), HL60 cells were not treated with nanoparticles. The diameter of the cells was about $10 \mu \mathrm{m}$, and the cells generally featured a regular spherical or spheroidal shape. Normal HL60 cells had the smooth surface, no flagellum, and plump cell type. The cell surface was not concave and convex, and the edge was relatively neat. As shown in Figures 10(c) and 10(d), HL60 cells were treated with $\mathrm{CdSe} / \mathrm{TiO}_{2}$ nanocomposite (CdSe-based nanocomposite $\mathrm{B}$ ). The shape of the cells was changed, with obvious concavity, convexity, and cracks on the surface, showing a flake-like arrangement like fish scales. The cell membrane was ruptured, and small holes appeared on the surface of the membrane, proving that HL60 cells were in the stage of apoptosis.

3.5. Mechanism of Photocatalysis on $C d X(X=S, T e, S e)$ Based Nanocomposites. As shown in Figure 11, the valence band electrons are excited, and they migrate to the conduction band after the nanoparticles absorb the light energy greater than the band gap energy under the irradiation with appropriate wavelength, thus producing carriers. In this process, part of the electron-hole pairs is effectively separated, migrating to the surface of the particles and interacting with molecules such as water and oxygen in the cellular environment. Water molecules adsorbed on the surface of the 


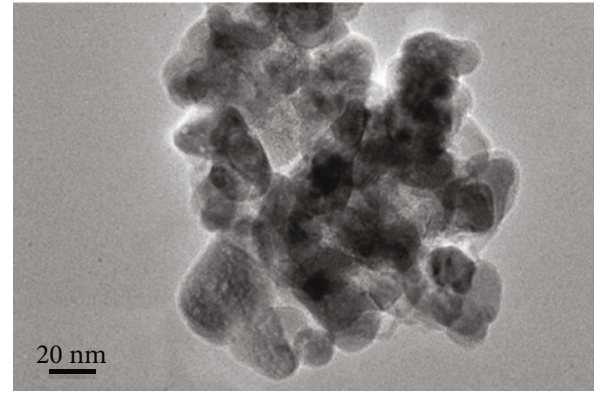

(a)

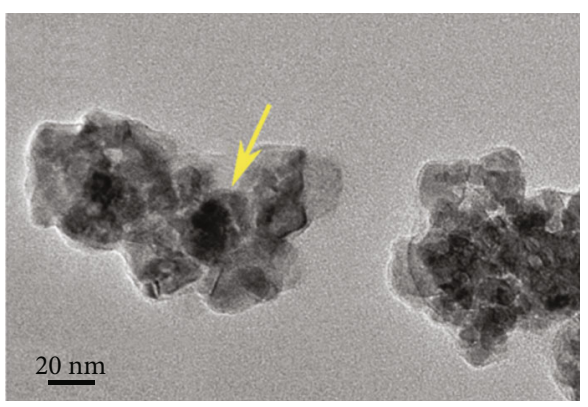

(b)

Figure 12: (a) The TEM images of $\mathrm{CdSe}-\mathrm{TiO}_{2}$; (b) the TEM images of CdSe-based nanocomposite C.

nanoparticles are oxidized by photogenerated holes, and oxygen molecules in the water are reduced by photogenerated electrons to generate active free radicals such as hydroxyl free radicals $(\cdot \mathrm{OH})$ and superoxide ions $\left(\mathrm{O}_{2}\right)$.

It is well known that the UV-Vis absorption spectrum of $\mathrm{TiO}_{2}$ has relatively high absorption in the ultraviolet region but weak absorption in visible light region, which is not conducive to being used as a visible light PDT drug. The absorption threshold of the UV-Vis absorption spectrum results can be calculated according to formula (2); the band gap energy of CdS, CdTe, and CdSe is 2.4, 2.36, and $1.95 \mathrm{eV}$, respectively. Since the $\mathrm{CdX}(\mathrm{X}=\mathrm{S}, \mathrm{Te}, \mathrm{Se})$ band gap is narrow and the position of valence band is positive, the $\mathrm{TiO}_{2}$ band gap energy $(3.2 \mathrm{eV})$ is high and the position of conduction band is low. As $\mathrm{X}$ is changed from $\mathrm{S}$, Te to Se, the more positive valence band position of CdSe QDs, the band gap of CdSe QDs is the narrowest. With the combination of CdX and $\mathrm{TiO}_{2}$, the photogenerated electrons of $\mathrm{CdX}$ can be rapidly injected into the lower conduction band of $\mathrm{TiO}_{2}$ due to the transfer of photogenerated carriers. The $\mathrm{CdX}(\mathrm{X}=\mathrm{S}$, $\mathrm{Te}, \mathrm{Se})-\mathrm{TiO}_{2}$ band gap becomes narrow and photogenerated carriers are easier to separate. The $\mathrm{CdSe}-\mathrm{TiO}_{2}$ band gap is the narrowest, with the lowest recombination rate and highest separation efficiency of carriers.

The efficiency of carrier trapping, migration, and conversion of the nanocomposites after doping with $\mathrm{CdX}(\mathrm{X}=\mathrm{S}$, $\mathrm{Te}, \mathrm{Se}) \mathrm{QDs}$ is changed by absorbing energy greater than the band gap energy. The lower the recombination rate of electrons and holes, the more photogenerated electrons and holes participate in redox reaction, which further enhances the photocatalytic activity of $\mathrm{TiO}_{2}$ shell and the yield of reactive oxygen species and increases the PDT inactivation efficiency finally.

3.6. Targeting Ability of $C d X \quad(X=S$, Se)-Based Nanocomposites Modified with Folic Acid. Studies show that folic acid is one of the most promising targeting ligands. Folate receptor has high sensitivity and specificity for folic acid and its analogs. Folate receptor mainly includes three subtypes: FR- $\alpha$, FR- $\beta$, and FR- $\gamma$. FR- $\alpha$ and FR- $\beta$ were overexpressed in cancer tissues but were rarely expressed in normal blood cells [34]. Folic acid modification with nanocomposite contributes to the targeted uptake of photosensitizers by cancer cells.

\subsubsection{Characterization of Folic Acid Molecule}

(1) TEM Studies of FA-CdSe-TiO 2 (CdSe-Based Nanocomposite $C$ ). Figure 12 is the TEM image of $\mathrm{CdSe}-\mathrm{TiO}_{2}$ nanocomposite prepared by the hydrolytic precipitation method and FA-CdSe- $\mathrm{TiO}_{2}$ nanocomposite (CdSe-based nanocomposite $\mathrm{C}$ ). $\mathrm{CdSe}-\mathrm{TiO}_{2}$ nanocomposite was spherical or spheroid, with certain dispersion, and size was about $30 \mathrm{~nm}$ shown in Figure 12(a). The dispersion of FA-CdSe$\mathrm{TiO}_{2}$ nanocomposite did not change significantly; a layer coated on the surface of nanoparticles could be observed (Figure 12(b) marked with an arrow). It proved that CdSe$\mathrm{TiO}_{2}$ nanocomposite modified with FA successfully, and nanocomposite size was about $40 \mathrm{~nm}$.

(2) Fourier Transform Infrared Spectra (FT-IR) of FA-CdS$\mathrm{TiO}_{2}$ (CdS-Based Nanocomposite B) and FA-CdSe-TiO (CdSe-Based Nanocomposite C). As shown in Figure 13(a), folic acid (curve A), CdS- $\mathrm{TiO}_{2}$ (curve B), and FA-CdS$\mathrm{TiO}_{2}$ (curve C) were as shown by FT-IR. The absorption peaks of 3314,3410 , and $3535 \mathrm{~cm}^{-1}$ in curve A were caused by the vibration of hydroxyl (-OH) and amino (NH-) in folic acid molecules. The absorption peaks of $726 \mathrm{~cm}^{-1}$ in curve $\mathrm{B}$ corresponded to the vibration of $\mathrm{O}-\mathrm{Ti}-\mathrm{O}$ bond, and the absorption peaks located at 1605 and $3352 \mathrm{~cm}^{-1}$ were caused by the vibration of hydroxyl $(-\mathrm{OH})$ on the surface of anatase $\mathrm{TiO}_{2}$. FT-IR (curve C) of FA-CdS- $\mathrm{TiO}_{2}$ nanocomposite, the hydroxyl peaks at 1605 and $3352 \mathrm{~cm}^{-1}$ disappeared or weakened, the absorption peaks corresponding to $\mathrm{C}-\mathrm{O}$ and $\mathrm{C}=\mathrm{O}$ bond vibration appeared at 1101 and $1638 \mathrm{~cm}^{-1}$, and the characteristic peaks corresponding to the amino group (NH-) in folic acid molecules emerged at $3459 \mathrm{~cm}^{-1}$. This demonstrated that the carboxyl group of folic acid was combined with the surface hydroxyl group of $\mathrm{CdS}-\mathrm{TiO}_{2}$ in the form of esterification.

As shown in Figure 13(b), FA-CdSe- $\mathrm{TiO}_{2}$ (curve A), folic acid (curve $\mathrm{B}$ ), and $\mathrm{CdSe}-\mathrm{TiO}_{2}$ (curve $\mathrm{C}$ ) were shown by FTIR. Absorption peaks of 3320 and $3540 \mathrm{~cm}^{-1}$ in curve $\mathrm{B}$ were caused by the vibration of hydroxyl (-OH) and amino (NH-) in folic acid molecules. The absorption peaks locating at $807 \mathrm{~cm}^{-1}$ in curve $\mathrm{C}$ corresponded to the vibration of O-Ti$\mathrm{O}$ bond, and the peaks at 1645 and $3313 \mathrm{~cm}^{-1}$ were caused by the vibration of hydroxyl $(-\mathrm{OH})$ on the surface of $\mathrm{TiO}_{2}$. In curve $\mathrm{A}$, the absorption peaks near 1645 and $3313 \mathrm{~cm}^{-1}$ 


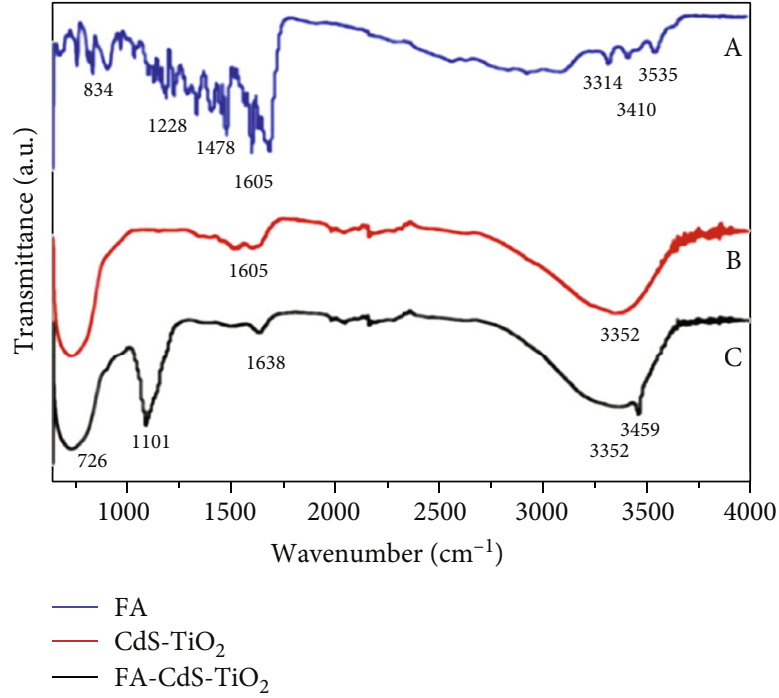

(a)

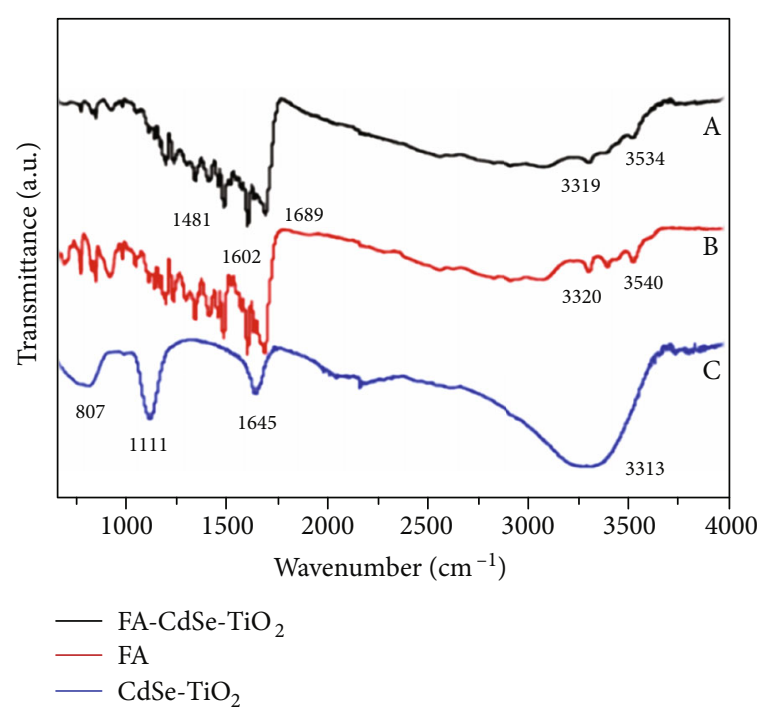

(b)

FIgure 13: (a) The FT-IR spectra of folic acid (curve A), CdS-TiO 2 (curve B), and FA-CdS-TiO 2 (curve C) (CdS-based nanocomposite B); (b) the FT-IR spectra of FA-CdSe- $\mathrm{TiO}_{2}$ (curve A) (CdSe-based nanocomposite C), folic acid (curve B), and CdSe-TiO 2 (Curve C).

disappeared or weakened, while the absorption peaks were similar to carboxylate (-COOM) appeared at $1481 \mathrm{~cm}^{-1}$, the characteristic peak of the stretching vibration of the pteridine ring of folic acid appeared at $1689 \mathrm{~cm}^{-1}$, and the absorption peaks corresponding to the vibration of the amino group (NH-) in folic acid molecules appeared around 3319 and $3534 \mathrm{~cm}^{-1}$. This demonstrated that the carboxyl group of folic acid was combined with the surface hydroxyl group of $\mathrm{CdSe}-\mathrm{TiO}_{2}$ in the form of esterification.

(3) FS Analysis of FA-CdS-TiO 2 (CdS-Based Nanocomposite $B)$. To detect the fluorescence intensity of $\mathrm{CdS}-\mathrm{TiO}_{2}$ and $\mathrm{FA}-\mathrm{CdS}-\mathrm{TiO}_{2}$ nanocomposite in solution and intracellular uptake of nanocomposites after 12 hours of incubation, respectively, it was found that the difference of fluorescence intensity between nanocomposite solution and after cellular uptake is smaller with FA modification. FA modification improved the cellular uptake efficiency of nanoparticles (Figure 14). FA-CdS- $\mathrm{TiO}_{2}$ nanocomposite had good biocompatibility.

(4) UV-Vis Spectroscopy of FA-CdSe-TiO ${ }_{2}$ (CdSe-Based Nanocomposite C). As shown in Figure 15, absorption spectra of $\mathrm{CdSe}-\mathrm{TiO}_{2}$ and $\mathrm{FA}-\mathrm{CdSe}-\mathrm{TiO}_{2}$ nanocomposites (CdSe-based nanocomposite $\mathrm{C}$ ) red-shifted to the visible light region in different degrees compared with that of pure $\mathrm{TiO}_{2}$, and the absorption intensity of FA-CdSe-TiO $\mathrm{T}_{2}$ slightly increased compared with $\mathrm{CdSe}-\mathrm{TiO}_{2}$ at $410 \mathrm{~nm}$. It indicated that the doping of CdSe effectively enhanced the visible light absorption of $\mathrm{TiO}_{2}$. After the modification of FA in proper proportion, it could still keep the effective visible light absorption of nanocomposite.

3.6.2. Cytotoxicity of FA-CdS- $\mathrm{TiO}_{2}$ (CdS-Based Nanocomposite B) and $\mathrm{FA}-\mathrm{CdSe}-\mathrm{TiO}_{2}$ (CdSe-Based Nanocomposite C) on HL60 Cells. As shown in Figure 16(a), the cell relative survival rate of the cells treated with $\mathrm{FA}-\mathrm{CdS}-\mathrm{TiO}_{2}$ nanocomposite was higher than $90 \%$ when the drug concentration was lower than $20 \mu \mathrm{g} / \mathrm{mL}$. When the drug concentration was 20,30 , and $40 \mu \mathrm{g} / \mathrm{mL}$, the survival rates of cells were $85 \%, 75 \%$, and $70 \%$, respectively, without irradiation. It indicated that the toxicity of FA-CdS- $\mathrm{TiO}_{2}$ nanocomposite at appropriate concentration to HL60 cells was lower. Compared with the CdS$\mathrm{TiO}_{2}$ group, the dark toxicity of FA-CdS- $\mathrm{TiO}_{2}$ nanocomposite decreased with the same concentration, and the decreasing trend increased with the increase of drug concentration. It indicated that FA-CdS- $\mathrm{TiO}_{2}$ nanocomposite after FA modification had good biocompatibility in low concentration range.

The effect of $\mathrm{CdSe}-\mathrm{TiO}_{2}$ and $\mathrm{FA}-\mathrm{CdSe}-\mathrm{TiO}_{2}$ nanocomposite modified with different $\mathrm{FA}$ ratios on the activity of HL60 cells without irradiation is shown in Figure 16(b). It could be seen that the relative survival rate of cells was maintained at above $80 \%$ treated with $\mathrm{FA}-\mathrm{CdSe}-\mathrm{TiO}_{2}$ nanocomposite with the FA modified ratios of $0.2,0.4,1.0$, and 2.0, respectively, without irradiation, when the mass concentration of the nanocomposite was less than $20 \mu \mathrm{g} / \mathrm{mL}$. The relative survival rate of cells decreased when the drug concentration gradually increased. In addition, when the proportion of FA was less than $100 \%$, the relative survival rate of cells decreased with the increase of the proportion of FA. It indicated that the targeting effect of folic acid molecules on HL60 cells improved the uptake efficiency of $\mathrm{FA}-\mathrm{CdSe}-\mathrm{TiO}_{2}$ nanocomposite. When the proportion of FA was increased to $200 \%$, cell viability increased compared with the nanocomposites with a lower proportion of FA without irradiation. This might be due to the large proportion of FA increasing, which reduced the proportion of $\mathrm{CdSe}$ in nanoparticles and thus reduced the toxicity of the drug itself.

As discussed above, it indicated that the modification of FA would not cause new cytotoxicity and might also reduce the toxicity of nanocomposites to a certain extent. 


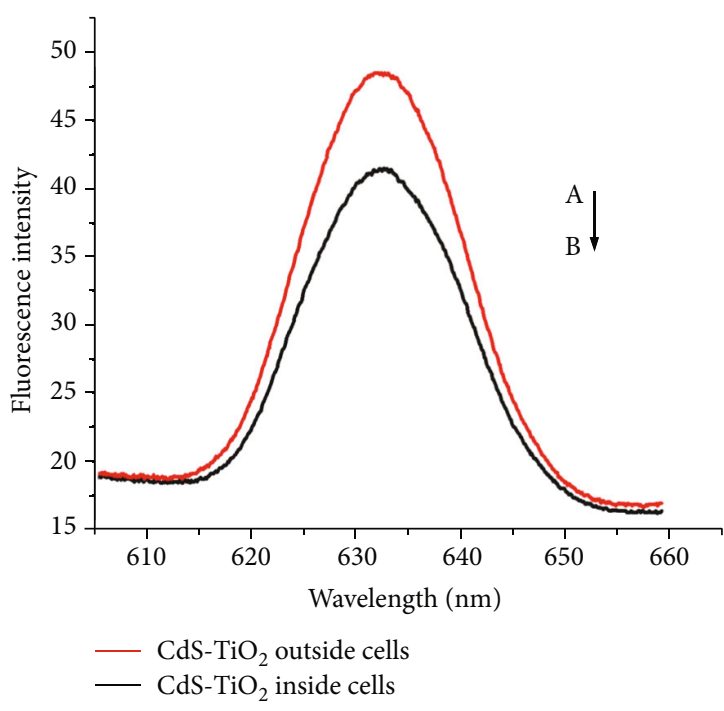

(a)

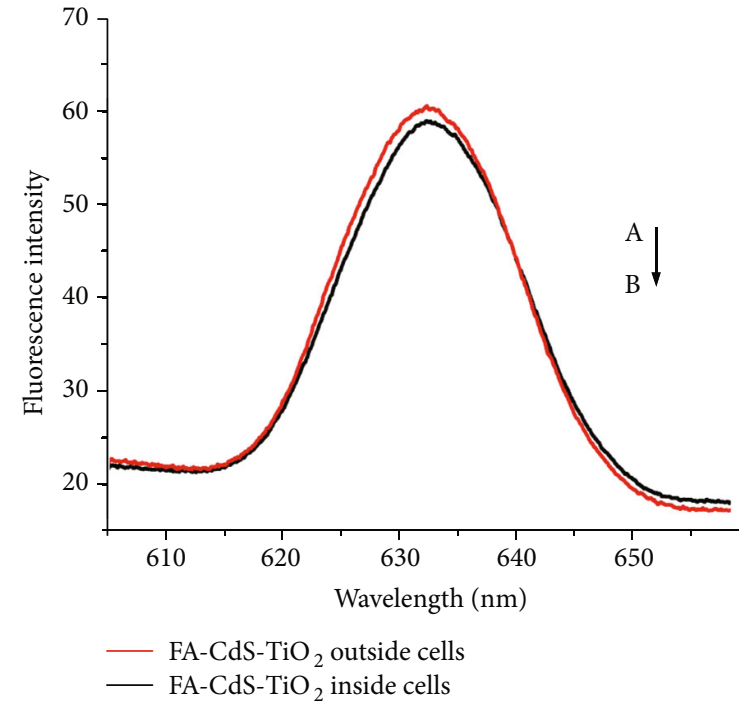

(b)

Figure 14: (a) The fluorescence emission spectrum of $\mathrm{CdS}-\mathrm{TiO}_{2}$ nanocomposite uptake by cells with the excitation wavelength of $410 \mathrm{~nm}$. (b) The fluorescence emission spectrum of CdS-based nanocomposite B uptake by cells with the excitation wavelength of $410 \mathrm{~nm}$.

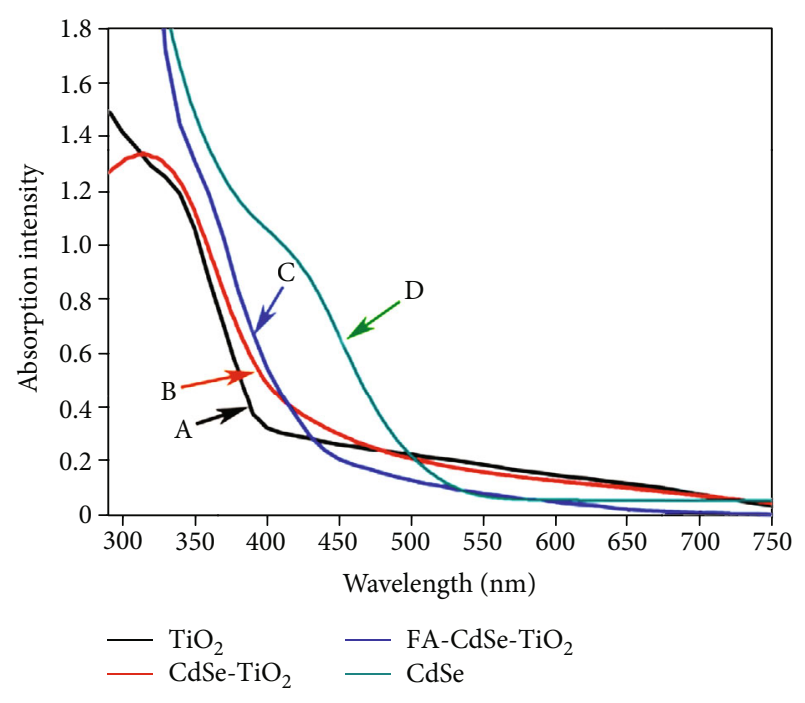

FIGURE 15: The UV-Vis absorption spectra of pure $\mathrm{TiO}_{2}$, CdSe, $\mathrm{CdSe}^{-\mathrm{TiO}_{2}}$ nanocomposite, and CdSe-based nanocomposite C.

3.6.3. Photodynamic Therapy of FA-CdS-TiO 2 (CdS-Based Nanocomposite B) and FA-CdSe-TiO 2 (CdSe-Based Nanocomposite C) on HL60 Cells. As shown in Figure 17(a), the PDT efficiency of the FA modified $\mathrm{CdS}-\mathrm{TiO}_{2}$ nanoparticles on HL60 cells was enhanced in comparison with that of $\mathrm{CdS}-\mathrm{TiO}_{2}$ in the increment of drug concentration. When the concentration of the nanoparticle drug was $40 \mu \mathrm{g} / \mathrm{mL}$, the PDT inactivation efficiency of FA-CdS- $\mathrm{TiO}_{2}$ nanocomposite reached the highest $80 \%$, while the $\mathrm{PDT}$ inactivation efficiency of $\mathrm{CdS}-\mathrm{TiO}_{2}$ nanocomposite was only about $54 \%$. According to the results of dark toxicity of nanocomposite on HL60 cells, it could be seen that the modification of FA not only reduced the dark toxicity of $\mathrm{CdS}-\mathrm{TiO}_{2}$ but also enhanced the PDT inactivation efficiency.
Figure 17(b) shows the PDT inactivation efficiency of $\mathrm{CdSe}-\mathrm{TiO}_{2}$ and FA-CdSe-TiO ${ }_{2}$ nanocomposite with different FA ratios on HL60 cells under different light intensities. According to the result of the dark toxicity of FA-CdSe-TiO, nanocomposite to HL60 cells, the mass concentration of nanocomposite was chosen as $20 \mu \mathrm{g} / \mathrm{mL}$, and the light dosages were 6,12 , and $18 \mathrm{~J} / \mathrm{cm}^{2}$, respectively. As shown in the figure, the PDT inactivation efficiency of $\mathrm{FA}-\mathrm{CdSe}-\mathrm{TiO}_{2}$ nanocomposite on HL60 cells was significantly improved compared with $\mathrm{CdSe}-\mathrm{TiO}_{2}$. With the increase of light intensity, PDT inactivation efficiency of different samples was improved. When the FA modification ratio was 1.0 and the light dosage was $18 \mathrm{~J} / \mathrm{cm}^{2}$, the PDT inactivation efficiency reached the highest $84 \%$. It was also found that when the ratio of FA was generally less than 1.0, the inactivation efficiency of FA-CdSe- $\mathrm{TiO}_{2}$ nanocomposite enhanced with the increase of the ratio of FA. Because folic acid molecules on FA-CdSe-TiO 2 nanocomposite surface could combine with FR overexpressed on the cancer cell membrane, it could promote absorption of nanocomposites by HL60 cells. More nanocomposites involving PDT reaction result in higher inactivation efficiency of HL60 cell. However, when the modification ratio of FA was increased to 2.0, the PDT inactivation efficiency was significantly decreased, which might be due to the excessive modification of FA on the surface that hindered the excitation of $\mathrm{CdSe}-\mathrm{TiO}_{2}$ by visible light.

Figure 17(c) shows the PDT inactivation efficiency of different samples at the concentration of $20 \mu \mathrm{g} / \mathrm{mL}$ and dosage of $18 \mathrm{~J} / \mathrm{cm}^{2}$. Low concentration and appropriate light intensity were conducive to comparing PDT efficiency of different materials. High concentration of nanomaterials could increase PDT efficiency but also lead to increase dark toxicity [51]. CdS- $\mathrm{TiO}_{2}$ (CdS-based nanocomposite A) when the ratio of $\mathrm{CdS}$ to $\mathrm{TiO}_{2}$ was 1.0 , the PDT inactivation efficiency reached 51\%. FA-CdS-TiO 2 nanocomposite (CdSbased nanocomposite $\mathrm{B}$ ) when the $\mathrm{FA}$ modification ratio 


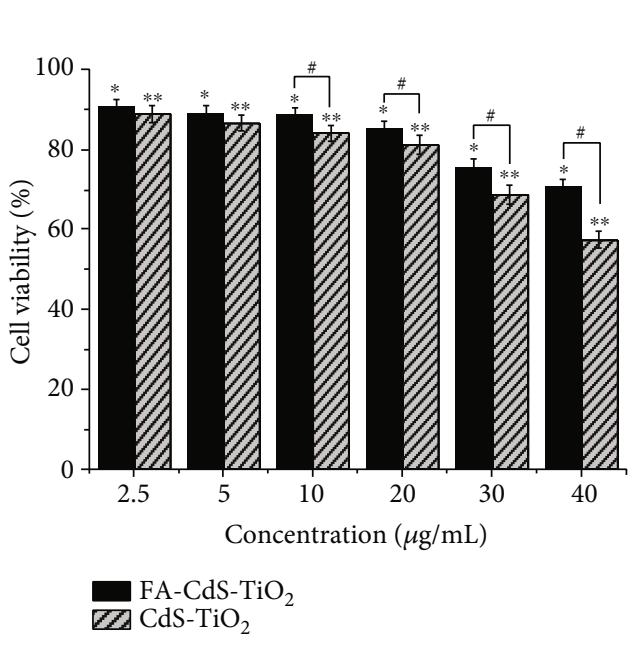

(a)

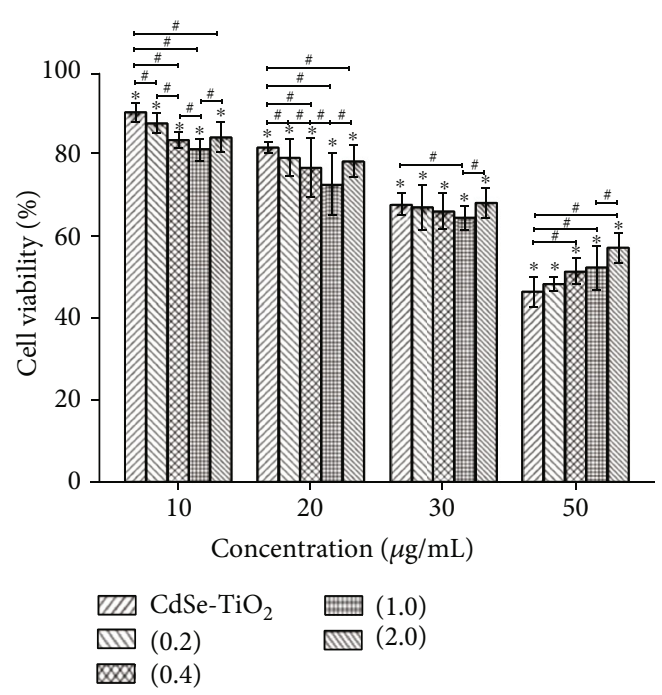

(b)

Figure 16: (a) Viability of HL60 cells treated with CdS-based nanocomposite B and CdS- $\mathrm{TiO}_{2}$ without irradiation for 24 hours. Each data point represents mean $\pm \mathrm{SD}(n=3) .{ }^{*} P<0.001$ indicated that there was a difference compared untreated control cells with groups of FA$\mathrm{CdS}-\mathrm{TiO}_{2}$ in different concentrations, ${ }^{* *} P<0.001$ indicated that there was a difference compared untreated control cells with groups of CdS- $\mathrm{TiO}_{2}$ in different concentrations, and ${ }^{\#} P<0.05$ compared with the two groups. (b) Viability of HL60 cells treated with CdSe-TiO 2 and CdSe-based nanocomposite $\mathrm{C}$ (with different folic acid ratios) in different concentrations without irradiation for 24 hours. Each data point represents mean $\pm \mathrm{SD}(n=3) .{ }^{*} P<0.001$ indicated that there was a difference compared with untreated control cells without irradiation, and ${ }^{\#} P<0.05$ compared with the two groups. All the data shown in the figure are representative.

was 1.0, the PDT inactivation efficiency reached $65.8 \%$. The PDT inactivation efficiency of $\mathrm{CdTe}^{-\mathrm{TiO}_{2}}$ (CdTe-based nanocomposite $\mathrm{B}$ ) and the hydroxyacetic acid-coated CdTe QDs (CdTe-based nanocomposite C) were 53.8\% and $42.3 \%$, respectively. The PDT efficiency of the hydroxyacetic acid-coated CdSe QDs (CdSe-based nanocomposite A) was $60.2 \%$. When the ratio of $\mathrm{CdSe}$ to $\mathrm{TiO}_{2}$ was 1.0 , the PDT inactivation efficiency of $\mathrm{CdSe}-\mathrm{TiO}_{2}$ reached $66.2 \%$. FA$\mathrm{CdSe}-\mathrm{TiO}_{2}$ nanocomposite (CdSe-based nanocomposite $\mathrm{C}$ ) when the folic acid modification ratio was 1.0 , the PDT inactivation efficiency reached the highest $84 \%$. These results concluded that the PDT inactivation efficiency of FA$\mathrm{CdSe}-\mathrm{TiO}_{2}$ nanocomposite (CdSe-based nanocomposite C) was the highest. Compared with the $\mathrm{CdX}-\mathrm{TiO}_{2}(\mathrm{X}=\mathrm{S}, \mathrm{Te}$, $\mathrm{Se}$ ) nanocomposites, the PDT inactivation efficiency of $\mathrm{CdSe}-\mathrm{TiO}_{2}$ was the highest whereas $\mathrm{CdS}-\mathrm{TiO}_{2}$ was the lowest. The possible reason is that the band gap of CdSe QDs was the narrowest so the $\mathrm{CdSe} Q \mathrm{QD}$ coupling with $\mathrm{TiO}_{2}$ promoted the photogenerated carrier separation of $\mathrm{CdSe}-\mathrm{TiO}_{2}$. The diameter of particles of $\mathrm{CdTe}-\mathrm{TiO}_{2}$ was larger resulting in low uptake of nanoparticles by HL60 cells. The PDT inactivation efficiency of $\mathrm{CdX}-\mathrm{TiO}_{2}(\mathrm{X}=\mathrm{Te}, \mathrm{Se})$ was higher than CdX QDs due to the CdX QD coupling with $\mathrm{TiO}_{2}$ that could promote the photogenerated carrier separation and charge transfer efficiency. The advantages of using $\mathrm{CdSe}-\mathrm{TiO}_{2}$ nanocomposite for PDT in comparison with previous works about $\mathrm{CdX}(\mathrm{X}=\mathrm{S}, \mathrm{Te}, \mathrm{Se})$ quantum dot modification were applied in different fields (see Table S1, Supporting Information). When the $\mathrm{CdX}-\mathrm{TiO}_{2}(\mathrm{X}=\mathrm{S}, \mathrm{Se})$ was modified with FA, the PDT inactivation efficiency was significantly increased. This was ascribed to a lot of folic acid molecules on FA-CdX-TiO $(\mathrm{X}=\mathrm{S}, \mathrm{Se})$ nanocomposite surface that could combine with
FR; it could promote absorption of nanoparticles by HL60 cells. The results clearly demonstrated that FA-CdSe- $\mathrm{TiO}_{2}$ nanocomposite (CdSe-based nanocomposite $\mathrm{C}$ ) was the best PDT nanomaterial.

3.6.4. Alteration of Reactive Oxygen Species in HL60 Cells after PDT. During photodynamic therapy, the photosensitizer transfers energy to the oxygen molecules in cells after being stimulated by visible light and produces a lot of highly oxidizing reactive oxygen species, resulting in the destruction of cell membranes or organelles, thereby killing cells $[52,53]$. The level of intracellular reactive oxygen species (ROS) induced by irradiation is an important indicator for the evaluation of a photosensitizer. In this series of experiments, the fluorescence probe labeling technology was used to analyze the ROS levels in HL60 cells by FS.

The level of reactive oxygen species in the cells treated with FA-CdS- $\mathrm{TiO}_{2}$ nanocomposite (CdS-based nanocomposite $\mathrm{B}$ ) and $\mathrm{CdS}-\mathrm{TiO}_{2}$ nanoparticle before and after visible light irradiation was shown in Figure 18(a). When the concentration of nanoparticles was $20 \mu \mathrm{g} / \mathrm{mL}$, the cells treated with FA-CdS- $\mathrm{TiO}_{2}$ nanocomposite produced significant amounts of reactive oxygen species after 40 minutes of irradiation. Compared with the $\mathrm{CdS}-\mathrm{TiO}_{2}$ nanoparticle cell group under the same condition, the yield of ROS in the FA-CdS- $\mathrm{TiO}_{2}$ group was significantly reduced without irradiation. However, the production of ROS of FA-CdS- $\mathrm{TiO}_{2}$ nanocomposite was significantly increased under irradiation.

Figure 18(b) shows the intracellular ROS level of HL60 cells after being treated by $\mathrm{CdSe}-\mathrm{TiO}_{2}$ and $\mathrm{FA}-\mathrm{CdSe}-\mathrm{TiO}_{2}$ nanocomposite (CdSe-based nanocomposite $\mathrm{C}$ ) with $100 \%$ FA. The intracellular ROS level in the FA-CdSe-TiO 2 -treated 


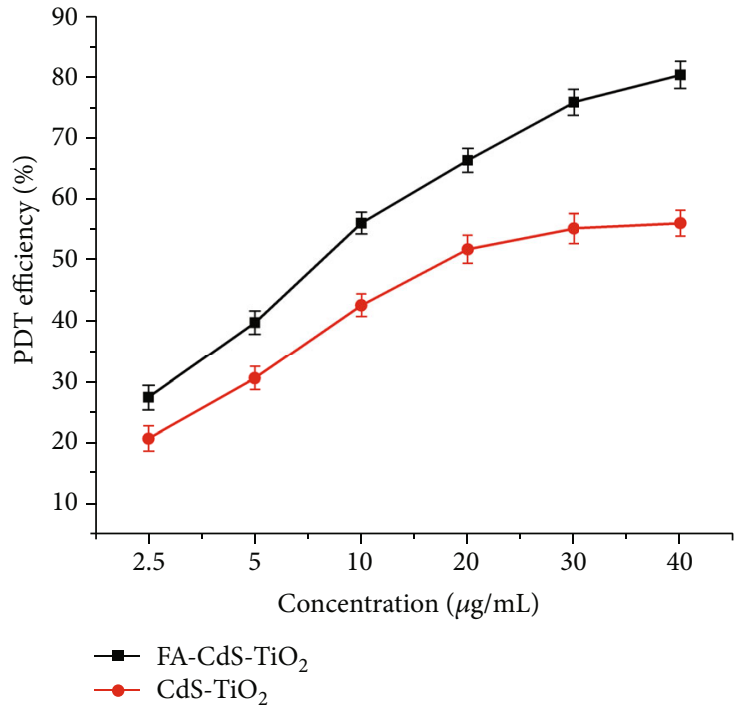

(a)

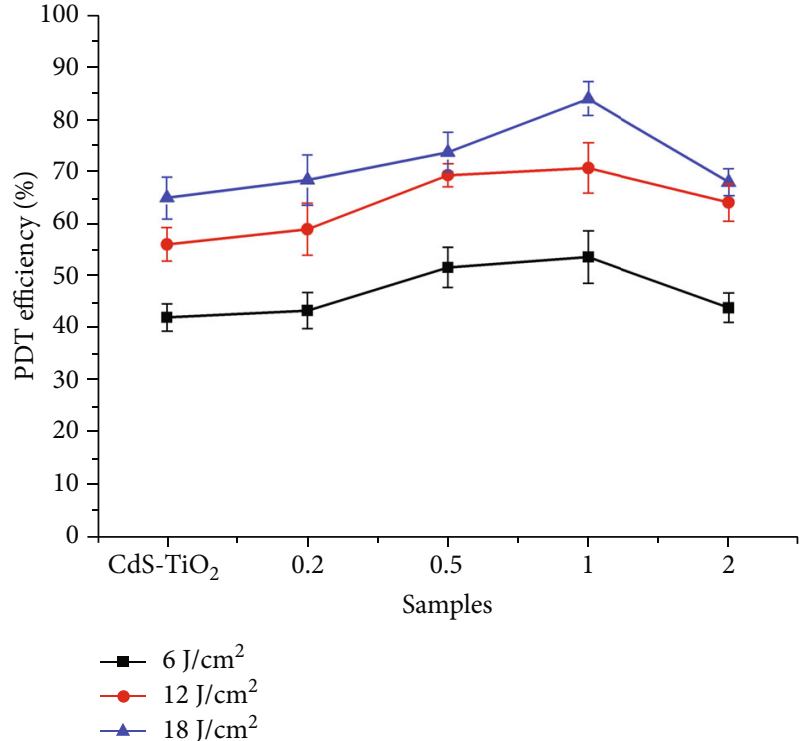

(b)

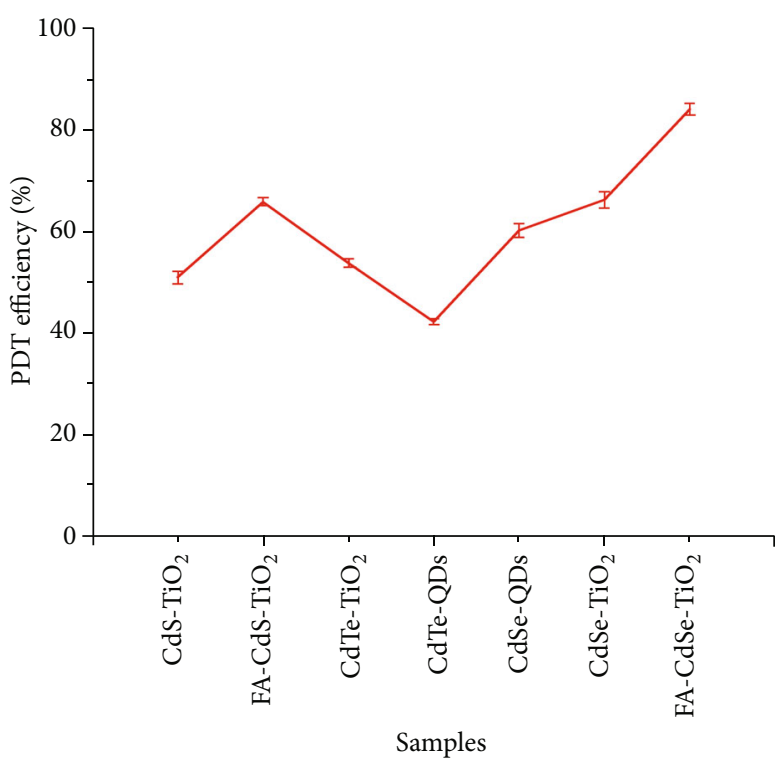

(c)

Figure 17: (a) The PDT efficiency of CdS-based nanocomposite $\mathrm{B}$ and $\mathrm{CdS}-\mathrm{TiO}_{2}$ on HL60 cells. Each data point represents mean \pm SD $(n=3)$. (b) The PDT efficiency of $\mathrm{CdSe}^{-\mathrm{TiO}_{2}}$ and CdSe-based nanocomposite $\mathrm{C}$ modified with different folic acid ratios on HL60 cells at different light dosages. Each data point represents mean \pm SD $(n=3)$. (c) The PDT efficiency of different samples at the concentration of $20 \mu \mathrm{g} / \mathrm{mL}$ and dosage of $18 \mathrm{~J} / \mathrm{cm}^{2}$. Each data point represents mean $\pm \mathrm{SD}(n=3)$. All the data shown in the figure are representative.

group was higher than that in the $\mathrm{CdSe}-\mathrm{TiO}_{2}$-treated group. The ROS level test result was consistent with the PDT efficiency test result described above (Figure 17(b)). These results indicated that FA modification could effectively improve the uptake of nanocomposites by HL60 cells, thus enhancing the photodynamic inactivation efficiency of HL60 cells.

3.6.5. Ultrastructural Morphology of the Treated Cells. Figure 19(a) shows normal HL60 cells with a cell diameter of about $8 \mu \mathrm{m}$ and a complete cell structure with clear outline and villous. Figure 19(b) is the ultrastructural diagram of HL60 cells after $\mathrm{CdSe}-\mathrm{TiO}_{2}$-mediated PDT. After coculture of $\mathrm{CdSe}-\mathrm{TiO}_{2}$ and HL60 cells with irradiation, the cell structure was damaged, and some cracks and pores were present on the cell membrane surface. The cells were incomplete and showed a tendency of lysis. It was supposed that $\mathrm{CdSe}-\mathrm{TiO}_{2}$ mainly accumulated on the surface of cell membrane and produced reactive oxygen species after visible light excitation, which caused damage to the cell membrane surface and eventually led to cell lysis and necrosis. Figures 19(c) and 19(d) are diagrams of multiple cells and a single cell after FA-CdSe- $\mathrm{TiO}_{2}$ nanocomposite (CdSebased nanocomposite C), and HL60 cells were incubated 


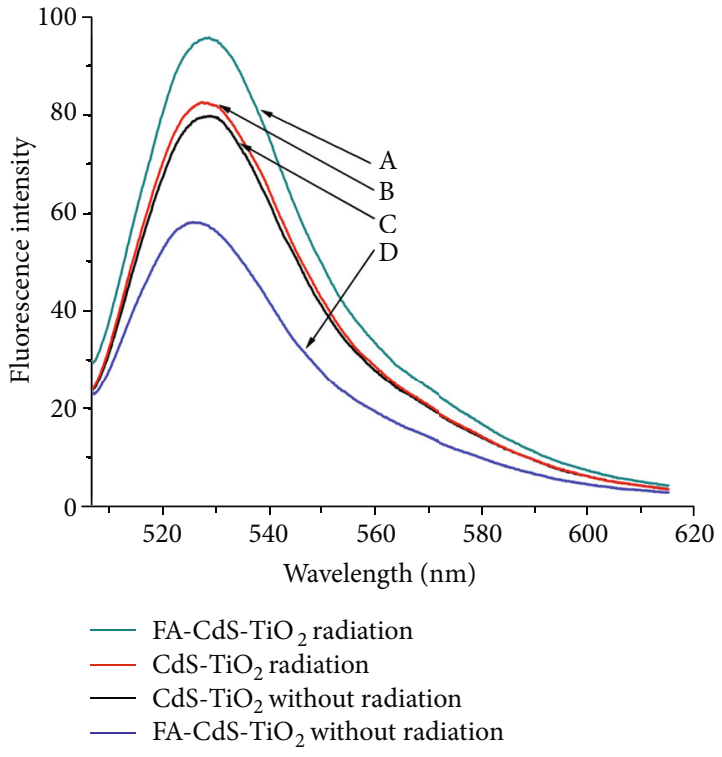

(a)

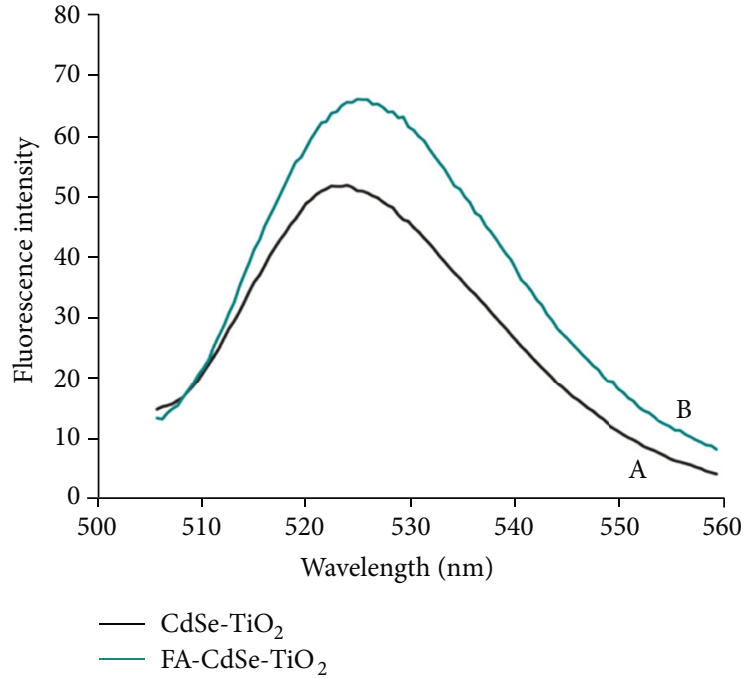

(b)

FIgURE 18: (a) The fluorescence spectra of reactive oxygen species probe in HL60 cells after PDT with the excitation wavelength of $485 \mathrm{~nm}$ (CdS-based nanocomposite B). (b) The fluorescence spectra of reactive oxygen species probe in HL60 cells after PDT with the excitation wavelength of $485 \mathrm{~nm}$ (CdSe-based nanocomposite C).

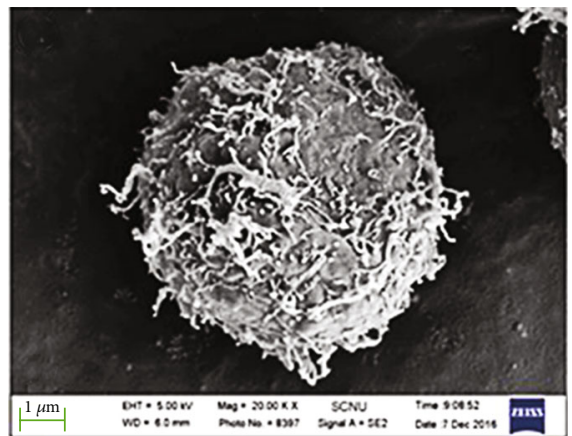

(a)

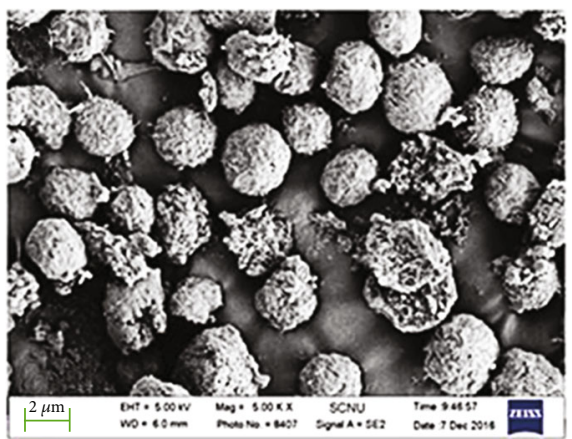

(c)

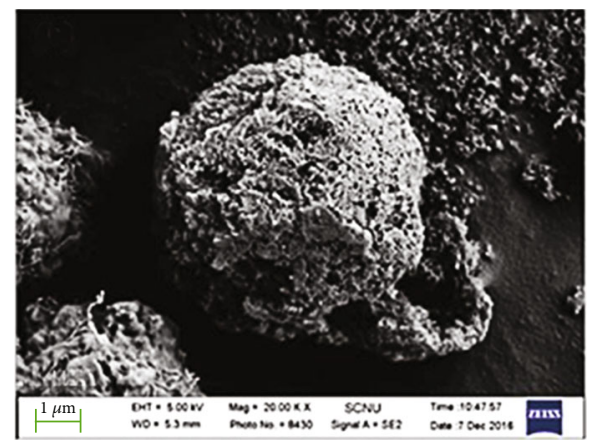

(b)

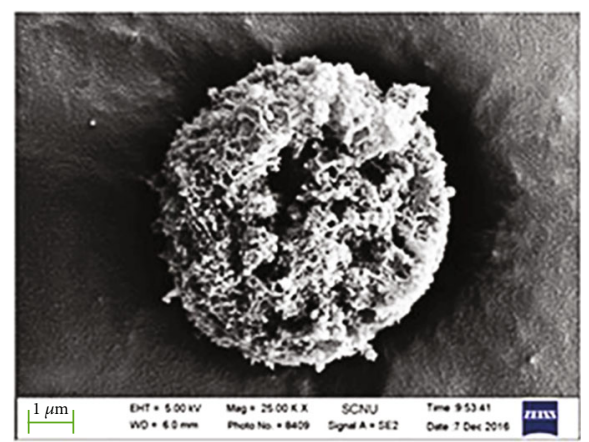

(d)

Figure 19: (a) The ultrastructural morphology of normal HL60 cell; (b) the ultrastructural morphology of the HL60 cell treated with CdSe$\mathrm{TiO}_{2}$ nanoparticles after PDT; (c) the ultrastructural morphology of the multiple HL60 cells treated with CdSe-based nanocomposite C after PDT; (d) the ultrastructural morphology of the single HL60 cell treated with CdSe-based nanocomposite C after PDT.

with irradiation, respectively. The cell structure was damaged seriously, and the cell membrane was severely ruptured and defective, and the organelle tissue was also damaged to a certain extent. The phenomenon may be related to FA-
CdSe- $\mathrm{TiO}_{2}$ nanocomposite entering the cells through endocytosis and nanocomposite accumulated on the surface of cell membrane producing a large amount of ROS after light excitation. ROS reacted with the organelle and cell 
<smiles>Nc1nc(=O)c2nc(CNc3ccc(C(=O)N=C(CCC(=O)O)C(=O)O)cc3)cnc2[nH]1</smiles>

Figure 20: The molecular structure of folic acid.

membrane by oxidation, resulting in the destruction of the organelle and cell membrane, thus leading to the necrosis of HL60 cells.

3.6.6. Mechanism of Photocatalysis on $C d X(X=S$, Se)-Based Nanocomposites Modified with Folic Acid. Figure 20 shows the molecular structure of FA. It could be found that FA contained a lot of carboxyl groups, while the surface of $\mathrm{TiO}_{2}$ contained a rich distribution of hydroxyl groups. It could be seen that carboxyl groups of folic acid molecules were combined with hydroxyl groups on the surface of $\mathrm{CdS}-\mathrm{TiO}_{2}, \mathrm{CdSe}-\mathrm{TiO}_{2}$ to form $\mathrm{FA}-\mathrm{CdS}-\mathrm{TiO}_{2}$, and $\mathrm{FA}-$ $\mathrm{CdSe}-\mathrm{TiO}_{2}$ by esterification reaction, respectively. Because FA could selectively target the FR that are overexpressed on the cell membrane of cancer cells, cancer cells can absorb more of the nanocomposites. It could enhance the photocatalytic activity and the yield of ROS in the photodynamic process and finally increase the PDT inactivation efficiency.

Based on all of these analysis results, it was indicated that FA-CdSe- $-\mathrm{TiO}_{2}$ has the highest PDT efficiency and low dark toxicity. Due to CdSe QDs having narrower band gap, it combined with $\mathrm{TiO}_{2}$ that can extend the visible response range of $\mathrm{TiO}_{2}$. The separation efficiency of photogenerated carriers was improved. When FA is modified on the surface of $\mathrm{CdSe}-\mathrm{TiO}_{2}$, FA could specifically recognize FR to improve the efficiency of HL60 cell uptake of nanocomposites. As the present clinical experiment is only in vitro, it has not been tested in vivo. The next step is to conduct experiments on mice in vivo, to further explore the possibility of human leukemia HL60 cells being exposed to the concentration of nanocomposites whether there is a health risk to humans.

\section{Conclusions}

In this paper, titanium dioxide was modified with quantum dots such as CdS, CdTe, and CdSe, and the particle size and spectral response range of novel nanocomposites were explored by a transmission electron microscope (TEM), XRay Diffraction pattern (XRD), and UV-visible absorption spectrum (UV-Vis). The large particle size of $\mathrm{CdTe}-\mathrm{TiO}_{2}$ was not conducive to the uptake of nanoparticles by HL60 cells. Nevertheless, the particle size of $\mathrm{CdSe}-\mathrm{TiO}_{2}$ was smaller and had a larger specific surface area; it was beneficial to participate in photoreaction. CdSe has the longest absorption cutoff wavelength and narrowest band gap. The spectral response range could be red-shifted to the visible region due to the narrow band gap of the doped quantum dots. It was used to improve the visible light response range of $\mathrm{TiO}_{2}$ under the visible light $410 \mathrm{~nm}$. Fluorescence spectroscopy (FS) was used to analyze the capture, migration, and transformation efficiency of $\mathrm{CdX}-\mathrm{TiO}_{2}$ nanocomposites. The doping of QDs reduced the recombination rate of electrons and holes on the surface, improving the separation efficiency of photogenerated carriers and photocatalytic activity. In addition to exploring the physical and chemical properties of $\mathrm{CdX}-\mathrm{TiO}_{2}$ nanocomposites, it was also necessary to detect the biological properties such as low dark toxicity to cells or its PDT efficiency to human acute promyeloid leukemia cell (HL60 cells). CdSe- $\mathrm{TiO}_{2}$ nanocomposite had lower dark toxicity and higher PDT inactivation efficiency. But $\mathrm{CdX}-\mathrm{TiO}_{2} \mathrm{NPs}$ were nonspecific targeting; thus, it was limited in its biological applications. To achieve more efficient cancer targeting, FA is used to modify the prepared $\mathrm{CdX}-\mathrm{TiO}_{2}$ NPs. Results of Fourier transform infrared spectroscopy (FT-IR) indicated FA compounds combine with $\mathrm{CdX}-\mathrm{TiO}_{2} \mathrm{NPs}$ in the form of esterification. The fluorescence probe labeling technology was used to analyze the higher ROS level in HL60 cells treated with FA-CdX- $-\mathrm{TiO}_{2}$ nanocomposite compared with $\mathrm{CdX}-\mathrm{TiO}_{2}$ after PDT by FS. Finally, serious damage to the ultrastructure of HL60 cells after treating with FA-CdSe-TiO ${ }_{2}$ nanocomposites for photodynamic therapy inactivation could be observed by the scanning electron microscope (SEM) compared with normal cells. It could be proved that reactive oxygen species were produced under irradiation which oxidized cell membranes and caused damage. Optimum PDT efficiency of FA-CdSe- $\mathrm{TiO}_{2}$ indicates that photocatalytic and targeting ability is much higher than pure $\mathrm{TiO}_{2}$ and $\mathrm{CdSe}-\mathrm{TiO}_{2}$. Furthermore, the mechanisms of improving the PDT efficiency and targeting of photodynamic therapy simultaneously by $\mathrm{CdX}(\mathrm{X}=\mathrm{S}$, Se)-based nanocomposites modified with FA are summarized. However, most QDs contain heavy metals, which would be toxic to normal cells and required further evaluation. As the present clinical experiment is only performed in vitro, the next step is to conduct experiments in vivo to further explore whether the FA-CdSe- $\mathrm{TiO}_{2}$ nanocomposite is a superior photosensitizer for treating leukemia to human body.

\section{Data Availability}

The data used to support the findings of this study are included within the article.

\section{Conflicts of Interest}

The authors declare that there is no conflict of interest regarding the publication of this paper. 


\section{Acknowledgments}

This work has been financially supported by the National Natural Science Foundation of China (61072029) and the Science and Technology Planning Project of Guangzhou City (2014J4100049).

\section{Supplementary Materials}

Figure S1: (a) Energy Dispersive Spectrometer (EDS) of CdS- $\mathrm{TiO}_{2}-0.2$ (CdS-based nanocomposite A). (b) X-ray photoelectron spectroscopy (XPS) of $\mathrm{CdTe}^{-\mathrm{TiO}_{2}}(\mathrm{CdTe}-$ based nanocomposite B). (c) EDS of FA-CdSe-TiO 2 (CdSebased nanocomposite $\mathrm{C}$ ). Table S1: comparisons between recent reports of $\mathrm{CdX}(\mathrm{X}=\mathrm{S}, \mathrm{Te}, \mathrm{Se})$ and our work. (Supplementary Materials)

\section{References}

[1] R. Alzeibak, T. A. Mishchenko, N. Y. Shilyagina, I. V. Balalaeva, M. V. Vedunova, and D. V. Krysko, "Targeting immunogenic cancer cell death by photodynamic therapy: past, present and future," Journal for Immunotherapy of Cancer, vol. 9, no. 1, 2021.

[2] S. Kwiatkowski, B. Knap, D. Przystupski et al., "Photodynamic therapy - mechanisms, photosensitizers and combinations," Biomedicine \& Pharmacotherapy, vol. 106, pp. 1098-1107, 2018.

[3] T. Hu, Z. Wang, W. Shen, R. Liang, D. Yan, and M. Wei, "Recent advances in innovative strategies for enhanced cancer photodynamic therapy," Theranostics, vol. 11, no. 7, pp. 32783300, 2021.

[4] V. N. Nguyen, Y. X. Yan, J. Z. Zhao, and J. Y. Yoon, "Heavyatom-free photosensitizers: from molecular design to applications in the photodynamic therapy of cancer," Accounts of Chemical Research, vol. 54, no. 1, pp. 207-220, 2021.

[5] N. Fu, X. C. Ren, and J. X. Wan, "The effect of molar ratios of $\mathrm{Ti} / \mathrm{Si}$ on core-shell $\mathrm{SiO}_{2} @ \mathrm{TiO}_{2}$ nanoparticles for photocatalytic applications," Journal of Nanomaterials, vol. 2020, Article ID 5312376, 11 pages, 2020.

[6] E. Fazio, A. M. Mezzasalma, L. D'Urso et al., "N-TiO 2 nanocatalysts: PLAL synthesis and photocatalytic activity," Journal of Nanomaterials, vol. 2020, Article ID 2901516, 10 pages, 2020.

[7] S. Abel, L. T. Jule, F. Belay et al., "Application of titanium dioxide nanoparticles synthesized by sol-gel methods in wastewater treatment," Journal of Nanomaterials, vol. 2021, Article ID 3039761, 6 pages, 2021.

[8] X. Y. Zhang, G. N. Zhang, M. Z. Chai, X. H. Yao, W. Y. Chen, and P. K. Chu, "Synergistic antibacterial activity of physicalchemical multi-mechanism by $\mathrm{TiO}_{2}$ nanorod arrays for safe biofilm eradication on implant," Bioactive Materials, vol. 6, no. 1, pp. 12-25, 2021.

[9] J. Kashyap, S. M. Ashraf, and U. Riaz, "Highly efficient photocatalytic degradation of amido black 10B dye using polycarbazole-decorated $\mathrm{TiO}_{2}$ nanohybrids," ACS Omega, vol. 2, no. 11, pp. 8354-8365, 2017.

[10] J. Wang, G. H. Wang, B. Cheng, J. G. Yu, and J. J. Fan, “Sulfurdoped $\mathrm{g}_{-} \mathrm{C}_{3} \mathrm{~N}_{4} / \mathrm{TiO}_{2}$ S-scheme heterojunction photocatalyst for Congo red photodegradation," Chinese Journal of Catalysis, vol. 42, no. 1, pp. 56-68, 2021.
[11] R. Imani, P. Veranic, A. Iglic, M. E. Kreft, M. Pazoki, and S. Hudoklin, "Combined cytotoxic effect of UV-irradiation and $\mathrm{TiO}_{2}$ microbeads in normal urothelial cells, low-grade and high-grade urothelial cancer cells," Photochemical \& Photobiological Sciences, vol. 14, no. 3, pp. 583-590, 2015.

[12] N. M. Bahadur, F. Chowdhury, M. Obaidullah et al., "Ultrasonic-assisted synthesis, characterization, and photocatalytic application of $\mathrm{SiO}_{2} @ \mathrm{TiO}_{2}$ core-shell nanocomposite particles," Journal of Nanomaterials, vol. 2019, Article ID 6368789, 11 pages, 2019.

[13] K. Q. Huang, L. Chen, J. G. Deng, and J. W. Xiong, "Enhanced visible-light photocatalytic performance of nanosized anatase $\mathrm{TiO}_{2}$ doped with CdS quantum dots for cancer-cell treatment," Journal of Nanomaterials, vol. 2012, 12 pages, 2012.

[14] K. Q. Lu, Q. Y. He, L. Chen, B. Q. Ai, and J. W. Xiong, “The comparative PDT experiment of the inactivation of HL60 on modified $\mathrm{TiO}_{2}$ nanoparticles," Journal of Nanomaterials, vol. 16, 8 pages, 2015 .

[15] Y. W. Zhang, J. S. Xu, J. Mei et al., "Strongly interfacialcoupled 2D-2D TiO$/ 2-\mathrm{C}_{3} \mathrm{~N}_{4}$ heterostructure for enhanced visible-light induced synthesis and conversion," Journal of Hazardous Materials, vol. 394, 2020.

[16] T. S. Zhou, J. C. Wang, S. Chen et al., "Bird-nest structured $\mathrm{ZnO} / \mathrm{TiO}_{2}$ as a direct $\mathrm{Z}$-scheme photoanode with enhanced light harvesting and carriers kinetics for highly efficient and stable photoelectrochemical water splitting," Applied Catalysis B-Environmental, vol. 267, 2020.

[17] T. K. Nideep, M. Ramya, and M. Kailasnath, “An investigation on the photovoltaic performance of quantum dot solar cells sensitized by CdTe, CdSe and CdS having comparable size," Superlattices and Microstructures, vol. 141, 2020.

[18] M. Hou, Z. Zhou, A. Xu et al., "Synthesis of group II-VI semiconductor nanocrystals via phosphine free method and their application in solution processed photovoltaic devices," Nanomaterials, vol. 11, no. 8, 2021.

[19] O. Cavdar, A. Malankowska, D. Amgar et al., "Remarkable visible-light induced hydrogen generation with $\mathrm{ZnIn}_{2} \mathrm{~S}_{4}$ microspheres/CuInS 2 quantum dots photocatalytic system," International Journal of Hydrogen Energy, vol. 46, no. 1, pp. 486-498, 2021.

[20] Y. Jiang, H. B. Shao, H. N. Xu et al., "Ultrafast synthesis of near-infrared-emitting aqueous $\mathrm{CdTe} / \mathrm{CdS}$ quantum dots with high fluorescence," Materials Today Chemistry, vol. 20, 2021.

[21] A. Ceja-Fdez, T. Lopez-Luke, J. Oliva et al., "Labeling of HeLa cells using $\mathrm{ZrO}_{2}: \mathrm{Yb}^{3+}-\mathrm{Er}^{3+}$ nanoparticles with upconversion emission," Journal of Biomedical Optics, vol. 20, no. 4, p. 046006, 2015.

[22] O. Savchuk, J. J. Carvajal Marti, C. Cascales et al., "Bifunctional $\mathrm{Tm}^{3+}, \mathrm{Yb}^{3+}: \mathrm{GdVO}_{4} @ \mathrm{SiO}_{2}$ core-shell nanoparticles in $\mathrm{HeLa}$ cells: upconversion luminescence nanothermometry in the first biological window and biolabelling in the visible," Nanomaterials, vol. 10, no. 5, p. 993, 2020.

[23] Y.-F. Ruan, X.-M. Shi, H.-Y. Wang, W.-W. Zhao, J.-J. Xu, and H.-Y. Chen, "CdS quantum dots modified photoelectrochemical biosensor for TATA-binding protein probing," Methods in Molecular Biology, vol. 2135, pp. 237-247, 2020.

[24] D. Guo, P. P. Xu, D. G. Chen et al., "Daunorubicin-loaded CdTe QDs conjugated with anti-CD123 mAbs: a novel delivery system for myelodysplastic syndromes treatment," International Journal of Nanomedicine, vol. 15, pp. 521-536, 2020. 
[25] J. Corredor, D. Harankahage, F. Gloaguen, M. J. Rivero, M. Zamkov, and I. Ortiz, "Influence of QD photosensitizers in the photocatalytic production of hydrogen with biomimetic [FeFe]-hydrogenase. Comparative performance of CdSe and CdTe," Chemosphere, vol. 278, p. 130485, 2021.

[26] J. H. Hua, M. Wang, Y. Jiao, H. Li, and Y. L. Yang, "Strongly coupled $\mathrm{CdX}(\mathrm{X}=\mathrm{S}$, Se and $\mathrm{Te})$ quantum dots/TiO 2 nanocomposites for photocatalytic degradation of benzene under visible light irradiation," Optik, vol. 171, pp. 95-106, 2018.

[27] A. Bansal, J. S. Sekhon, and S. S. Verma, "Effect of surrounding medium on light absorption characteristics of CdSe, CdS \& CdTe nanospheres and their comparison," in International Conference on Recent Trends in Applied Physics and Material Science (RAM), pp. 267-268, Amer Inst Physics, Govt Coll Engn \& Technol Bikaner, Bikaner, India, 2013.

[28] P. Bernasconi and O. Borsani, "Targeting leukemia stem cell-niche dynamics: a new challenge in AML treatment," Journal of Oncology, vol. 2019, Article ID 8323592, 12 pages, 2019.

[29] D. Vetrie, G. V. Helgason, and M. Copland, “The leukaemia stem cell: similarities, differences and clinical prospects in CML and AML," Nature Reviews Cancer, vol. 20, no. 3, pp. 158-173, 2020.

[30] J. F. Ross, H. Wang, F. G. Behm et al., "Folate receptor type beta is a neutrophilic lineage marker and is differentially expressed in myeloid leukemia," Cancer, vol. 85, no. 2, pp. 348-357, 1999.

[31] H. Wang, X. Zheng, F. G. Behm, and M. Ratnam, "Differentiation-independent retinoid induction of folate receptor type beta, a potential tumor target in myeloid leukemia," Blood, vol. 96, no. 10, pp. 3529-3536, 2000.

[32] B. W. Blaser, M. Gonit, H. Qi et al., "Induction of folate receptor type beta in a bone marrow engraftment model of acute myelogenous leukemia," Leukemia, vol. 21, no. 10, 2007.

[33] G. Marverti, C. Marraccini, A. Martello et al., "Folic acidpeptide conjugates combine selective cancer cell internalization with thymidylate synthase dimer interface targeting," Journal of Medicinal Chemistry, vol. 64, no. 6, pp. 32043221, 2021.

[34] M. Jurczyk, K. Jelonek, M. Musial-Kulik, A. Beberok, D. Wrzesniok, and J. Kasperczyk, "Single-versus dualtargeted nanoparticles with folic acid and biotin for anticancer drug delivery," Pharmaceutics, vol. 13, no. 3, p. 326, 2021.

[35] Q. Zhang, S. N. Deng, J. L. Liu et al., "Cancer-targeting graphene quantum dots: fluorescence quantum yields, stability, and cell selectivity," Advanced Functional Materials, vol. 29, no. 5, p. 1805860, 2019.

[36] H. Zhang, L. P. Wang, H. M. Xiong, L. H. Hu, B. Yang, and W. Li, "Hydrothermal synthesis for high-quality CdTe nanocrystals," Advanced Materials, vol. 15, no. 20, pp. 1712-1715, 2003.

[37] H. Johnston, D. M. Brown, N. Kanase et al., "Mechanism of neutrophil activation and toxicity elicited by engineered nanomaterials," Toxicology In Vitro, vol. 29, no. 5, pp. 1172-1184, 2015.

[38] O. M. Bondarenko, M. Heinlaan, M. Sihtmae et al., "Multilaboratory evaluation of 15 bioassays for (eco) toxicity screening and hazard ranking of engineered nanomaterials: FP7 project NANOVALID," Nanotoxicology, vol. 10, no. 9, pp. 12291242, 2016.

[39] Y. Y. Song, Y. H. Zhang, R. J. Li, W. Chen, C. K. A. Chung, and Z. W. Cai, "The cellular effects of $\mathrm{PM}_{2.5}$ collected in Chinese Taiyuan and Guangzhou and their associations with polycyclic aromatic hydrocarbons (PAHs), nitro-PAHs and hydroxyPAHs," Ecotoxicology and Environmental Safety, vol. 191, 2020.

[40] B. V. Yesudhason, J. Christyraj, M. Ganesan et al., "Developmental stages of zebrafish (Danio rerio) embryos and toxicological studies using foldscope microscope," Cell Biology International, vol. 44, no. 10, pp. 1968-1980, 2020.

[41] R. G. Ricarte, T. P. Lodge, and M. A. Hillmyer, "Detection of pharmaceutical drug crystallites in solid dispersions by transmission electron microscopy," Molecular Pharmaceutics, vol. 12, no. 3, pp. 983-990, 2015.

[42] T. M. David, K. I. Gnanasekar, P. Wilson, P. Sagayaraj, and T. Mathews, "Effect of $\mathrm{Ni}, \mathrm{Pd}$, and Pt nanoparticle dispersion on thick films of $\mathrm{TiO}_{2}$ nanotubes for hydrogen sensing: TEM and XPS studies," ACS Omega, vol. 5, no. 20, pp. 1135211360, 2020.

[43] A. O. Bokuniaeva and A. S. Vorokh, "Estimation of particle size using the Debye equation and the Scherrer formula for polyphasic $\mathrm{TiO}_{2}$ powder," Journal of Physics: Conference Series, vol. 1410, 2019.

[44] Y.-S. Li, F.-L. Jiang, Q. Xiao et al., "Enhanced photocatalytic activities of $\mathrm{TiO}_{2}$ nanocomposites doped with water-soluble mercapto-capped CdTe quantum dots," Applied Catalysis BEnvironmental, vol. 101, no. 1-2, pp. 118-129, 2010.

[45] P. Thevenot, J. Cho, D. Wavhal, R. B. Timmons, and L. Tang, "Surface chemistry influences cancer killing effect of $\mathrm{TiO}_{2}$ nanoparticles," Nanomedicine-Nanotechnology Biology and Medicine, vol. 4, no. 3, pp. 226-236, 2008.

[46] S. S. Lee, H. Kim, D. K. Sohn et al., "Indocyanine green-loaded injectable alginate hydrogel as a marker for precision cancer surgery," Quantitative Imaging in Medicine and Surgery, vol. 10, no. 3, pp. 779-788, 2020.

[47] A. K. Zhanataev, E. A. Anisina, A. V. Kulakova et al., "Genotoxicity of cationic lipopeptide nanoparticles," Toxicology Letters, vol. 328, pp. 1-6, 2020.

[48] D. Bagdas, A. Jackson, M. Carper, R. Y. T. Chen, L. S. Akinola, and M. I. Damaj, "Impact of menthol on nicotine intake and preference in mice: concentration, sex, and age differences," Neuropharmacology, vol. 179, p. 108274, 2020.

[49] M. Naushad, T. Ahamad, K. A. Al-Ghanim, A. H. Al-Muhtaseb, G. E. Eldesoky, and A. A. Khan, "A highly porous nanocomposite $\left(\mathrm{Fe}_{3} \mathrm{O}_{4} @ \mathrm{BFR}\right)$ for the removal of toxic $\mathrm{Cd}(\mathrm{II})$ ions from aqueous environment: adsorption modelling and regeneration study," Composites Part B-Engineering, vol. 172, pp. 179-185, 2019.

[50] S. Hu, M. R. Shaner, J. A. Beardslee, M. Lichterman, B. S. Brunschwig, and N. S. Lewis, "Amorphous $\mathrm{TiO}_{2}$ coatings stabilize $\mathrm{Si}, \mathrm{GaAs}$, and $\mathrm{GaP}$ photoanodes for efficient water oxidation," Science, vol. 344, no. 6187, pp. 1005-1009, 2014.

[51] A. Kakade, E. S. Salama, F. Pengya, P. Liu, and X. K. Li, "Longterm exposure of high concentration heavy metals induced toxicity, fatality, and gut microbial dysbiosis in common carp, _Cyprinus carpio_," Environmental Pollution, vol. 266, p. 115293, 2020.

[52] Z. J. Zhou, J. B. Song, L. M. Nie, and X. Y. Chen, "Reactive oxygen species generating systems meeting challenges of photodynamic cancer therapy," Chemical Society Reviews, vol. 45, no. 23, pp. 6597-6626, 2016.

[53] J. Krajczewski, K. Rucinska, H. E. Townley, and A. Kudelski, "Role of various nanoparticles in photodynamic therapy and detection methods of singlet oxygen," Photodiagnosis and Photodynamic Therapy, vol. 26, pp. 162-178, 2019. 